\title{
Discovery of an Isothiazolinone-Containing Antitubercular Natural Product Levesquamide
}

\section{Libang Liang ${ }^{\dagger}$, Bradley Haltli ${ }^{\ddagger}$, , Douglas H. Marchbank ${ }^{\dagger, \S}$, Maike Fischer ${ }^{1}$, Christopher}

W. Kirby ${ }^{\dagger}, 1$, Hebelin Correa§, Trevor N. Clark», Christopher A. Gray"l^, Russell G. Kerr*,†,њ\&

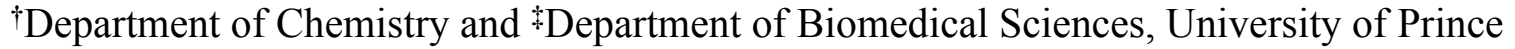
Edward Island, 550 University Avenue, Charlottetown, PE C1A 4P3, Canada

\$Nautilus Biosciences Croda, 550 University Avenue, Regis and Joan Duffy Research Centre, Charlottetown, PE C1A 4P3, Canada

${ }^{1}$ Charlottetown Research \& Development Centre, Agriculture and Agri-Food Canada, 440 University Avenue, Charlottetown, PE C1A 4N6, Canada

"Department of Chemistry, University of New Brunswick, 30 Dineen Drive, Fredericton, NB E3B 5A3, Canada

${ }^{\wedge}$ Department of Biological Sciences, University of New Brunswick, 100 Tucker Park Road, Saint John, NB E2L 4L5, Canada 


\section{Table of Contents}

\section{Spectroscopic Data}

Mass spectroscopy spectra

Figure S1. High-resolution mass spectra of levesquamide $[\mathrm{M}+\mathrm{H}]^{+}$. (S4)

Figure S2. Tandem mass spectrum $\mathrm{MS}^{2}$ of levesquamide $[\mathrm{M}+\mathrm{H}]^{+}$. (S5)

\section{NMR spectra of levesquamide}

Figure S3. ${ }^{1} \mathrm{H}$ NMR (600 MHz) spectrum of levesquamide (1) in DMSO- $d_{6}$. (S6)

Figure S4. ${ }^{13} \mathrm{C}$ NMR (150 MHz) spectrum of levesquamide (1) in DMSO- $d_{6}$. (S7)

Figure S5. COSY NMR (600 MHz) spectrum of levesquamide (1) in DMSO- $d_{6}$. (S7)

Figure S6. ${ }^{1} \mathrm{H}-{ }^{13} \mathrm{C}$ HSQC NMR $(600 / 150 \mathrm{MHz})$ spectrum of levesquamide (1) in $\mathrm{DMSO}_{6} \cdot(\mathrm{S} 8)$

Figure S7. ${ }^{1} \mathrm{H}-{ }^{13} \mathrm{C}$ HMBC NMR $(600 / 150 \mathrm{MHz}, \mathrm{J}=5 \mathrm{~Hz})$ spectrum of levesquamide (1) in DMSO- $d_{6}$. (S9)

Figure S8. ${ }^{1} \mathrm{H}-{ }^{13} \mathrm{C}$ HMBC NMR (400 / $\left.100 \mathrm{MHz}, \mathrm{J}=3 \mathrm{~Hz}\right)$ spectrum of levesquamide (1) in DMSO- $d_{6}$. (S10)

Figure S9. ${ }^{1} \mathrm{H}-{ }^{15} \mathrm{~N}$ HMBC NMR $(600 / 60 \mathrm{MHz}, \mathrm{J}=5 \mathrm{~Hz})$ spectrum of levesquamide (1) in DMSO- $d_{6}$. (S11)

Figure S10. ${ }^{1} \mathrm{H}^{15}{ }^{15} \mathrm{HMBC}$ NMR $(400 / 40 \mathrm{MHz}, \mathrm{J}=1 \mathrm{~Hz})$ spectrum of ${ }^{15} \mathrm{~N}-$ labeled levesquamide in MeOD. (S12)

Figure S11. 1D selective ROESY NMR (400 MHz) spectrum of levesquamide (1) in $\mathrm{DMSO}-d_{6}$. (S13)

Figure S12. UDEFT ${ }^{13} \mathrm{C}$ NMR spectrum of $\mathrm{L}-\left[1,2,3-{ }^{13} \mathrm{C}_{3},{ }^{15} \mathrm{~N}\right]$ cysteine and sodium $\left[1,2-{ }^{13} \mathrm{C}_{2}\right]$ acetate labeled levesquamide (1). (S14)

\section{IR and UV spectra of levesquamide}

Figure S13. IR spectrum of levesquamide. (S15)

Figure S14. UV spectrum of levesquamide. (S16)

\section{Marfey's analysis of levesquamide}

Figure S15. Marfey's analysis of serine and isoserine in levesquamide. (S16)

Figure S16. Marfey's analysis of leucinol in levesquamide. (S17) 


\section{Levesquamide biosynthetic gene cluster and inactivation of $l v q F$.}

Figure S17. Inactivation scheme of $l v q F$. (S18)

Figure S18. Production of levesquamide in wild-type (WT), mutant and complemented strains. (S19)

Figure S19. Chemical analysis of $l v q F$ deletion. (S20)

Table S1. Biosynthetic gene cluster of levesquamide predicted by AntiSMASH 5.0.0. (S21)

Table S2. Analysis of the LvqA CAL domain specificityconferring residues according to the 10 aa code. (S25)

Table S3. Analysis of the levesquamide NRPS A domains specificity conferring residues according to the 10 aa code. (S26)

Table S4. PCR primers in the study. (S27)

\section{References (S28)}




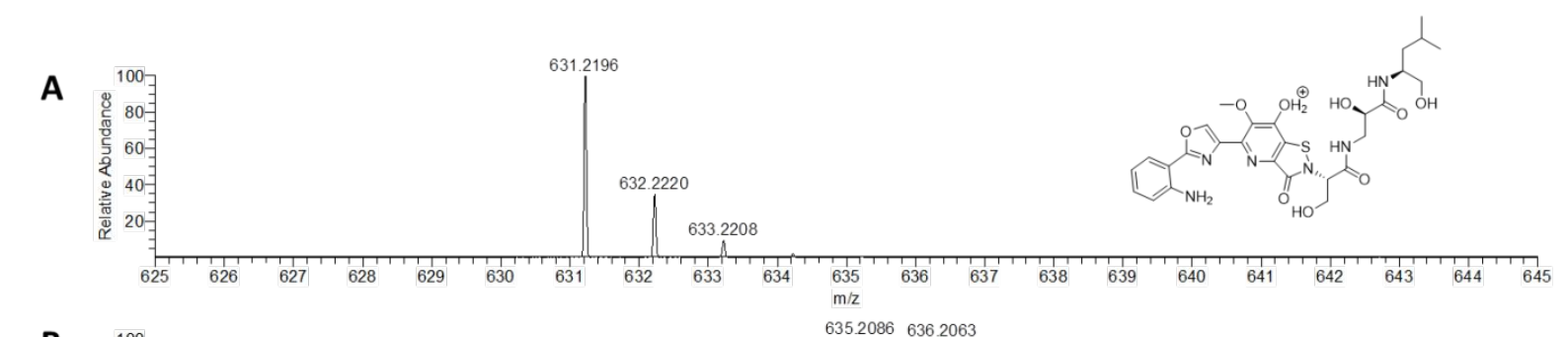

B

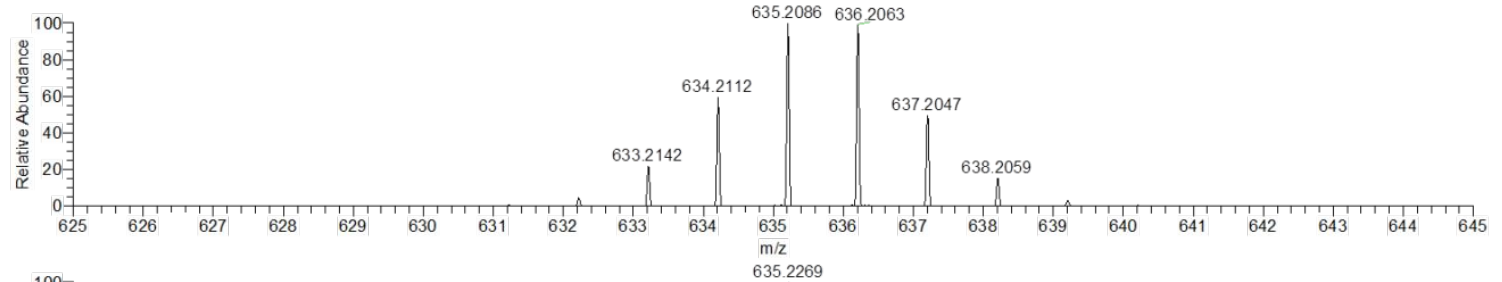

C

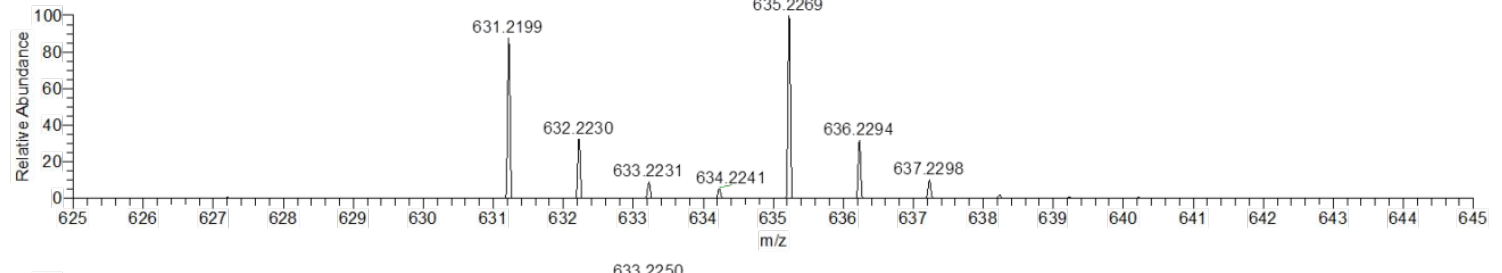

D

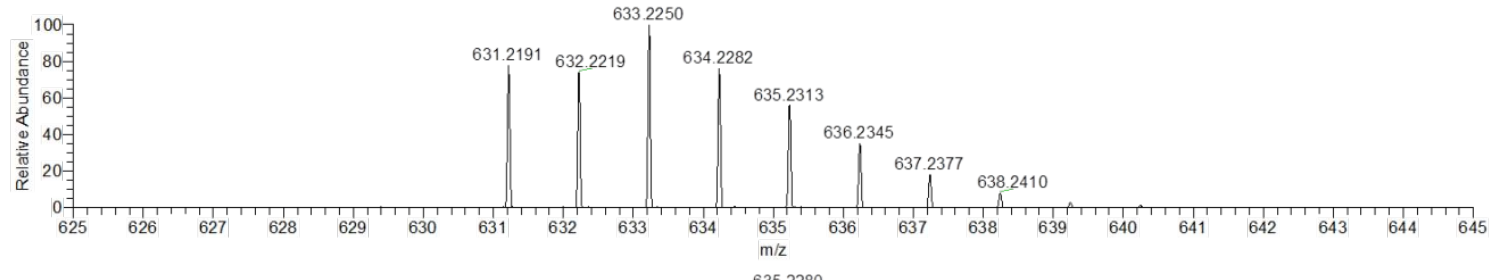

$\mathbf{E}$

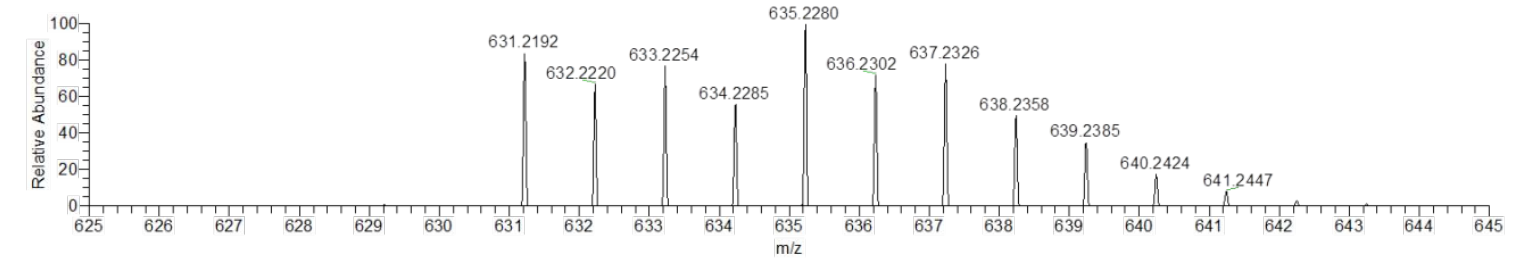

Figure S1. High-resolution mass spectra of levesquamide $[\mathrm{M}+\mathrm{H}]^{+}:$(A) unlabeled; (B) $\left[{ }^{15} \mathrm{~N}\right]$ ammonium chloride labeled; (C) L- $\left[1,2,3-{ }^{13} \mathrm{C}_{3},{ }^{15} \mathrm{~N}\right]$ cysteine labeled; (D) sodium $\left[1,2-{ }^{13} \mathrm{C}_{2}\right]$ acetate; $(\mathrm{E}) \mathrm{L}-\left[1,2,3-{ }^{13} \mathrm{C}_{3},{ }^{15} \mathrm{~N}\right]$ cysteine and sodium $\left[1,2-{ }^{13} \mathrm{C}_{2}\right]$ acetate labeled. 
T: FTMS + p ESI Full ms2 631.21@cid35.00 [170.00-2000.00]

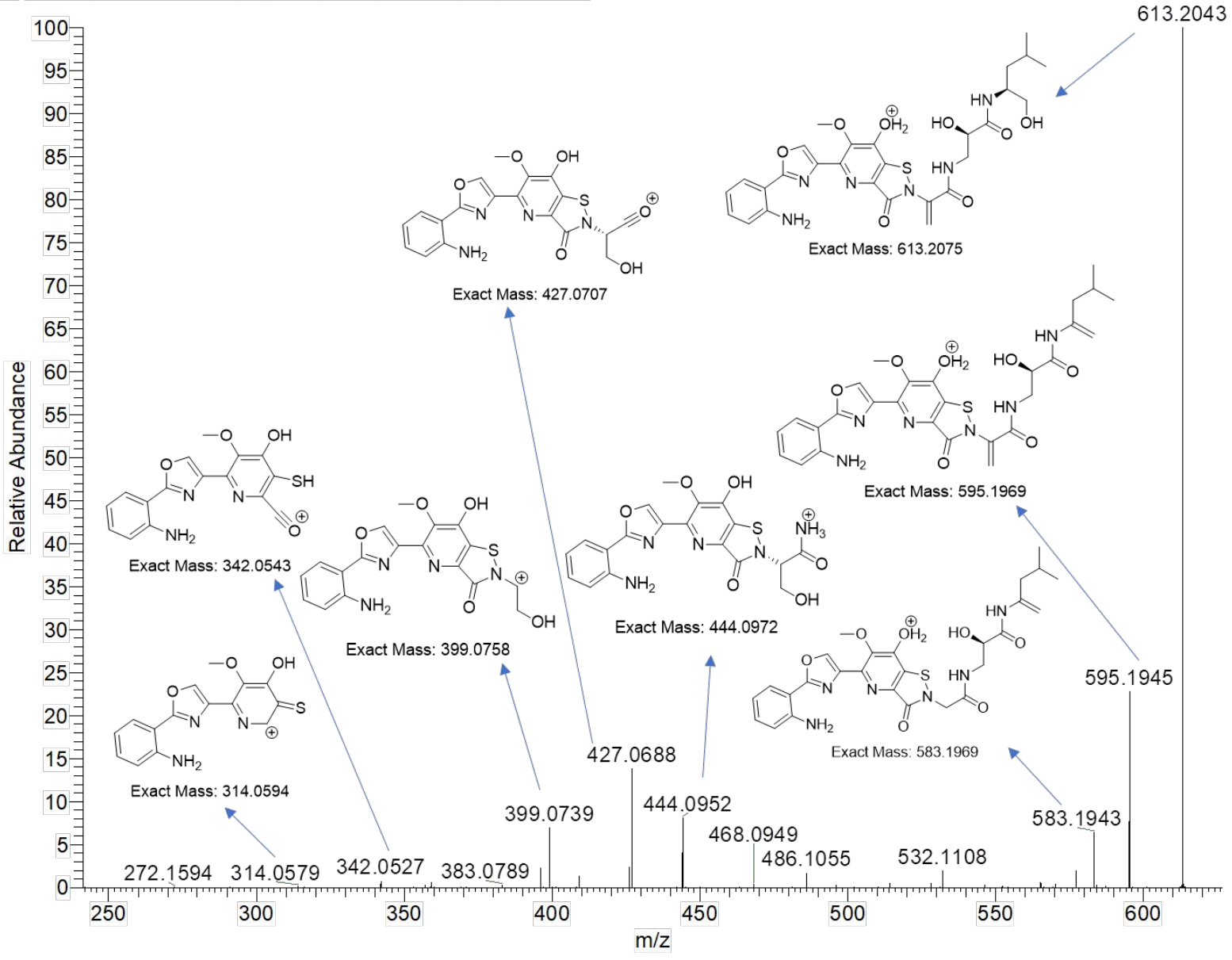

Figure S2. Tandem mass spectrum $\left(\mathrm{MS}^{2}\right)$ of levesquamide $\mathrm{m} / z$ 631.21 $[\mathrm{M}+\mathrm{H}]^{+}$And annotation of fragment ions. 


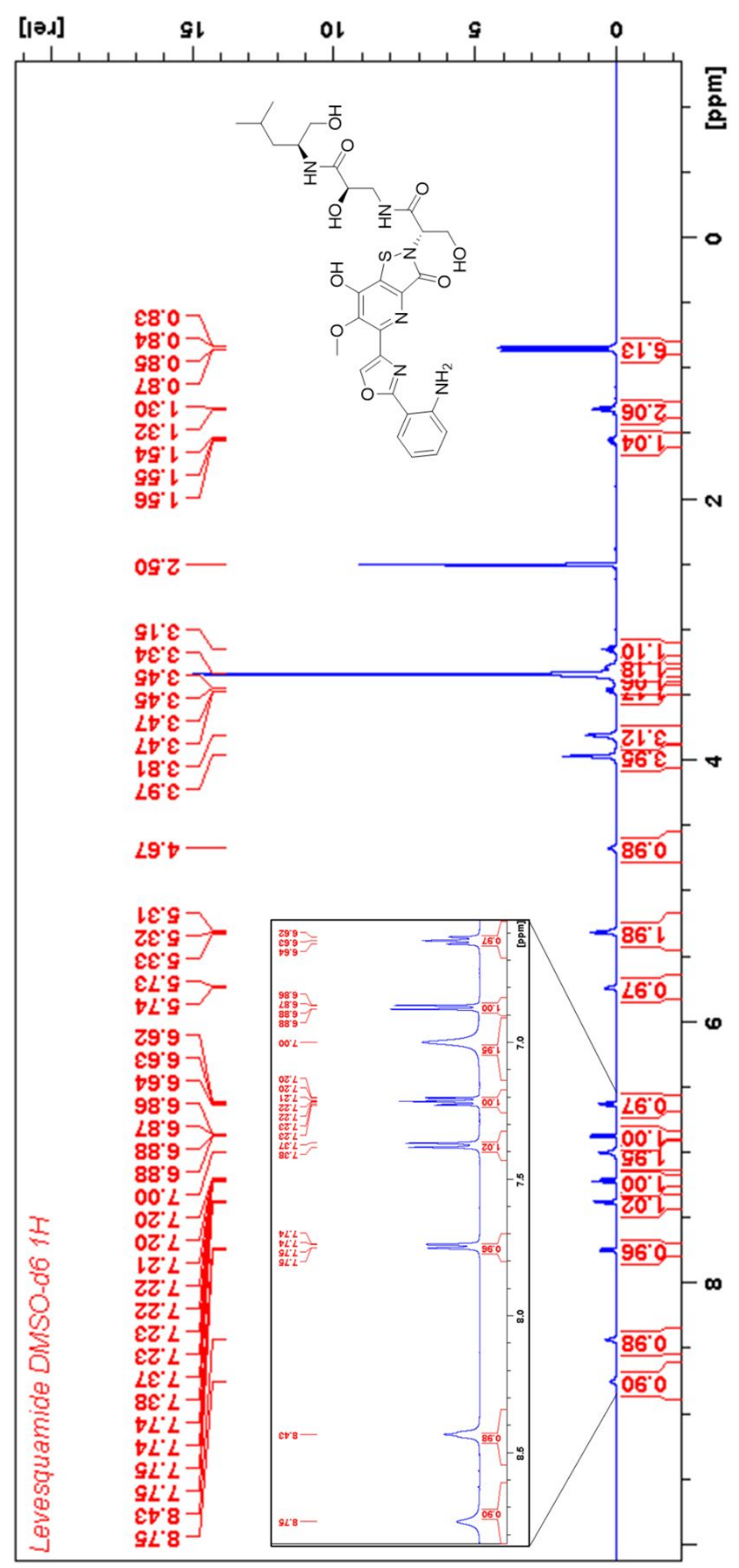

Figure S3. ${ }^{1} \mathrm{H}$ NMR $(600 \mathrm{MHz})$ spectrum of levesquamide (1) in DMSO- $d_{6}$. 


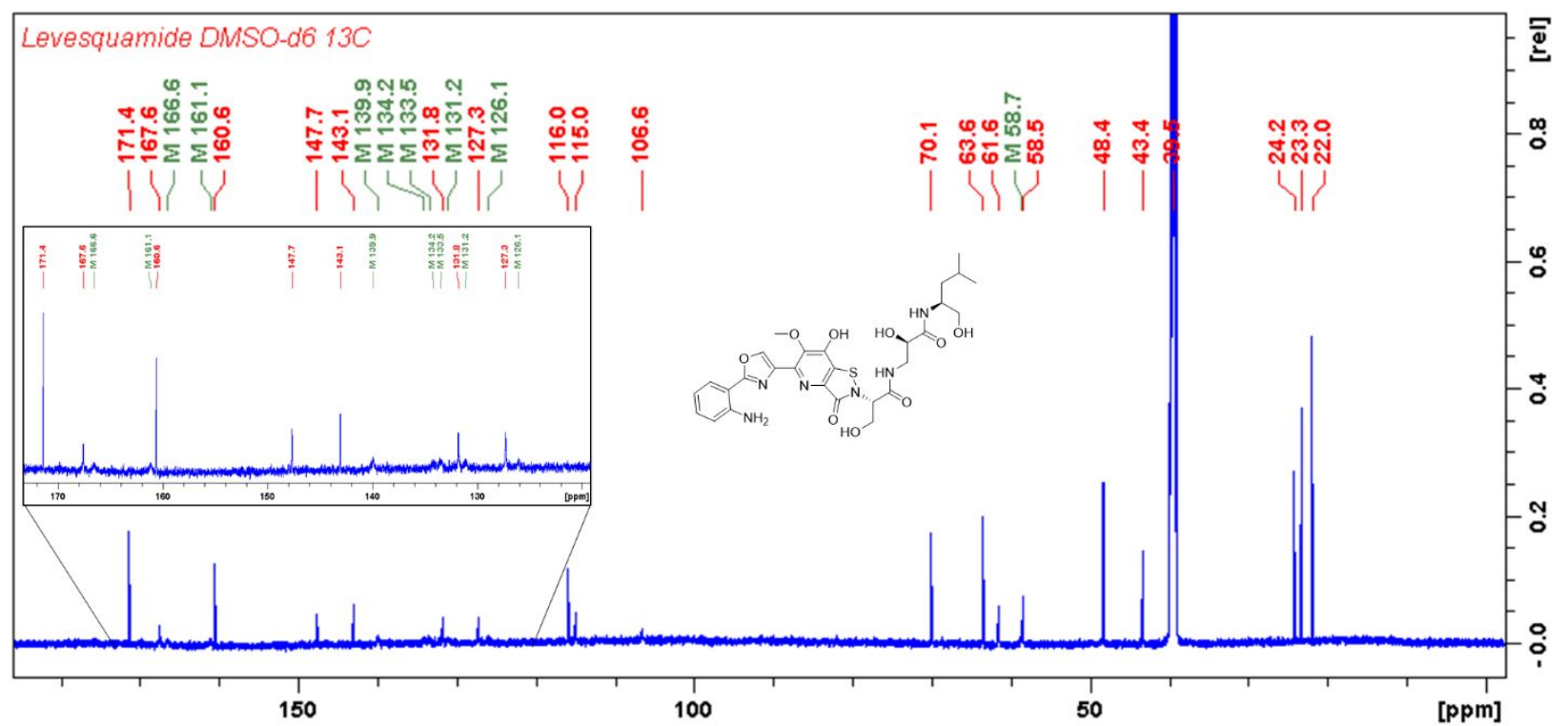

Figure S4. ${ }^{13} \mathrm{C}$ NMR (150 MHz) spectrum of levesquamide (1) in DMSO- $d_{6}$.

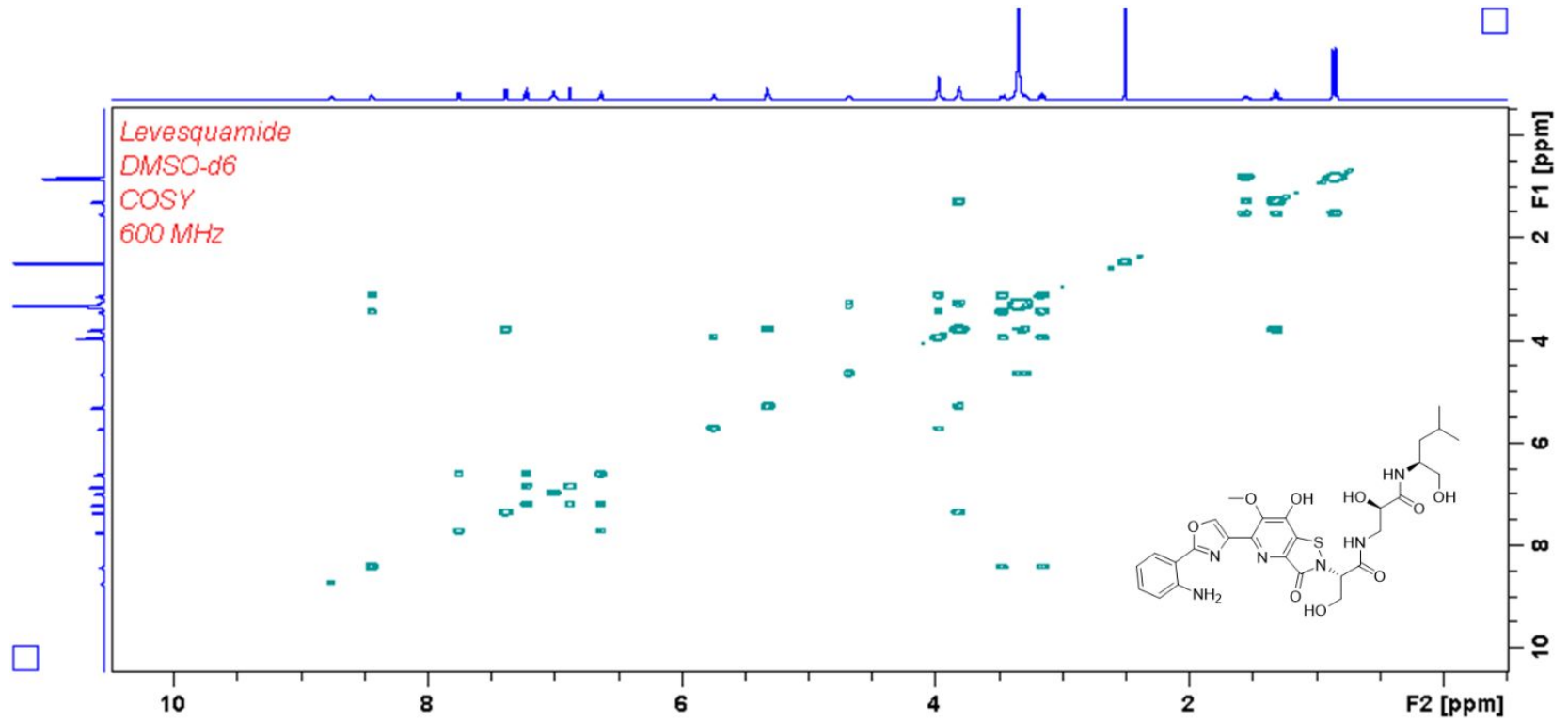

Figure S5. COSY NMR (600 MHz) spectrum of levesquamide (1) in DMSO- $d_{6}$. 


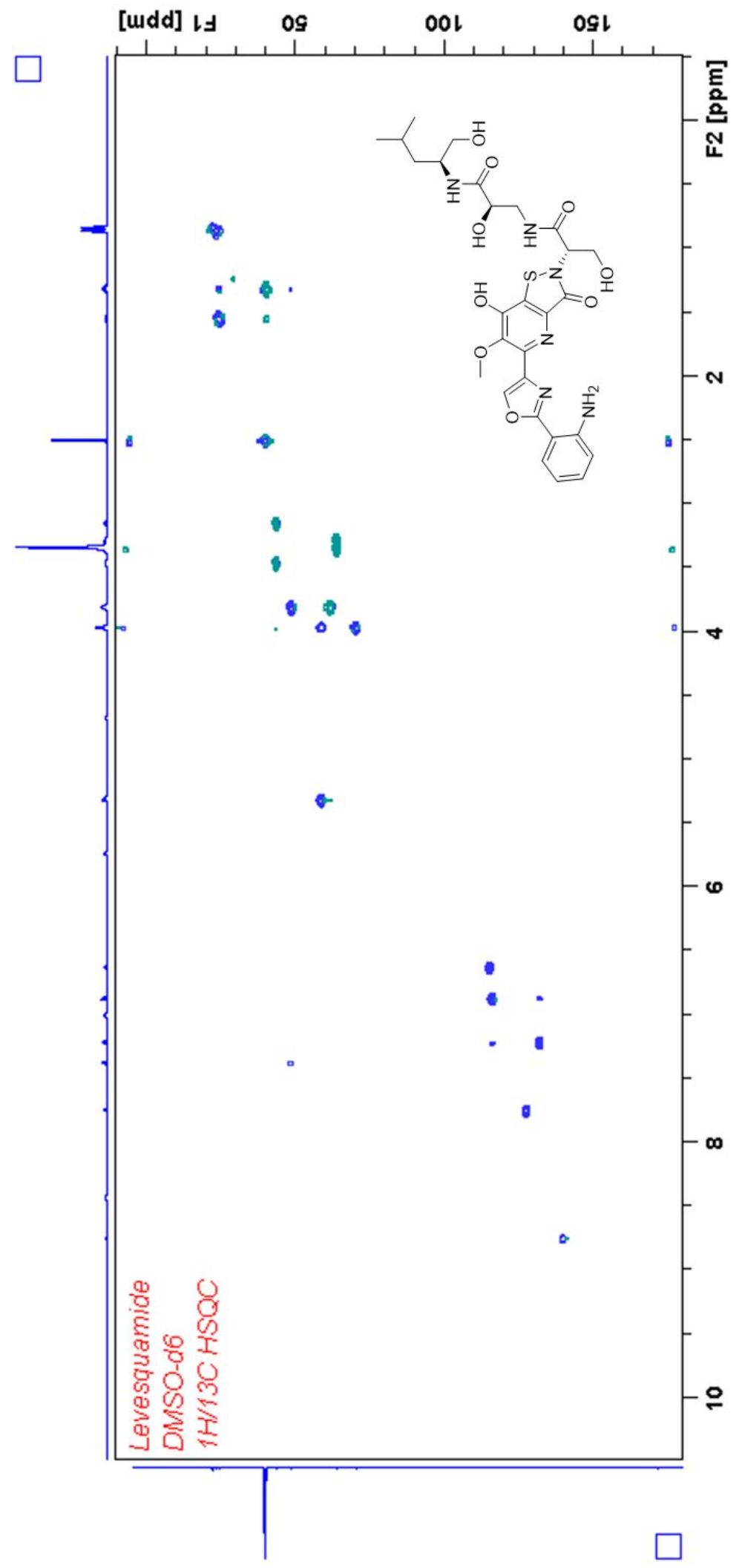

Figure S6. ${ }^{1} \mathrm{H}-{ }^{13} \mathrm{C}$ HSQC NMR (600 / $\left.150 \mathrm{MHz}\right)$ spectrum of levesquamide (1) in DMSO- $d_{6}$. 


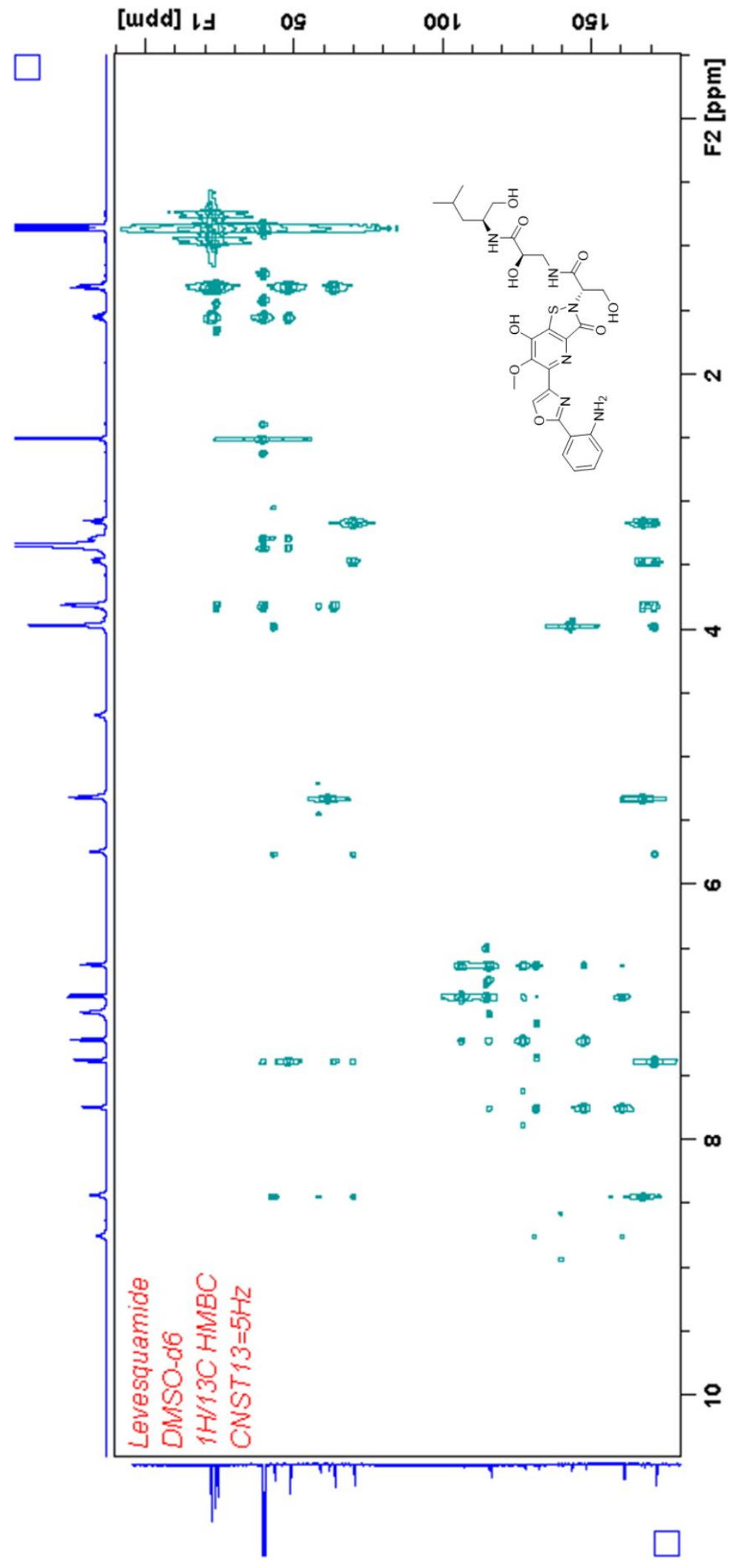

Figure S7. ${ }^{1} \mathrm{H}-{ }^{13} \mathrm{C}$ HMBC NMR (600 / $\left.150 \mathrm{MHz}, \mathrm{J}=5 \mathrm{~Hz}\right)$ spectrum of levesquamide (1) in DMSO- $d_{6}$. 


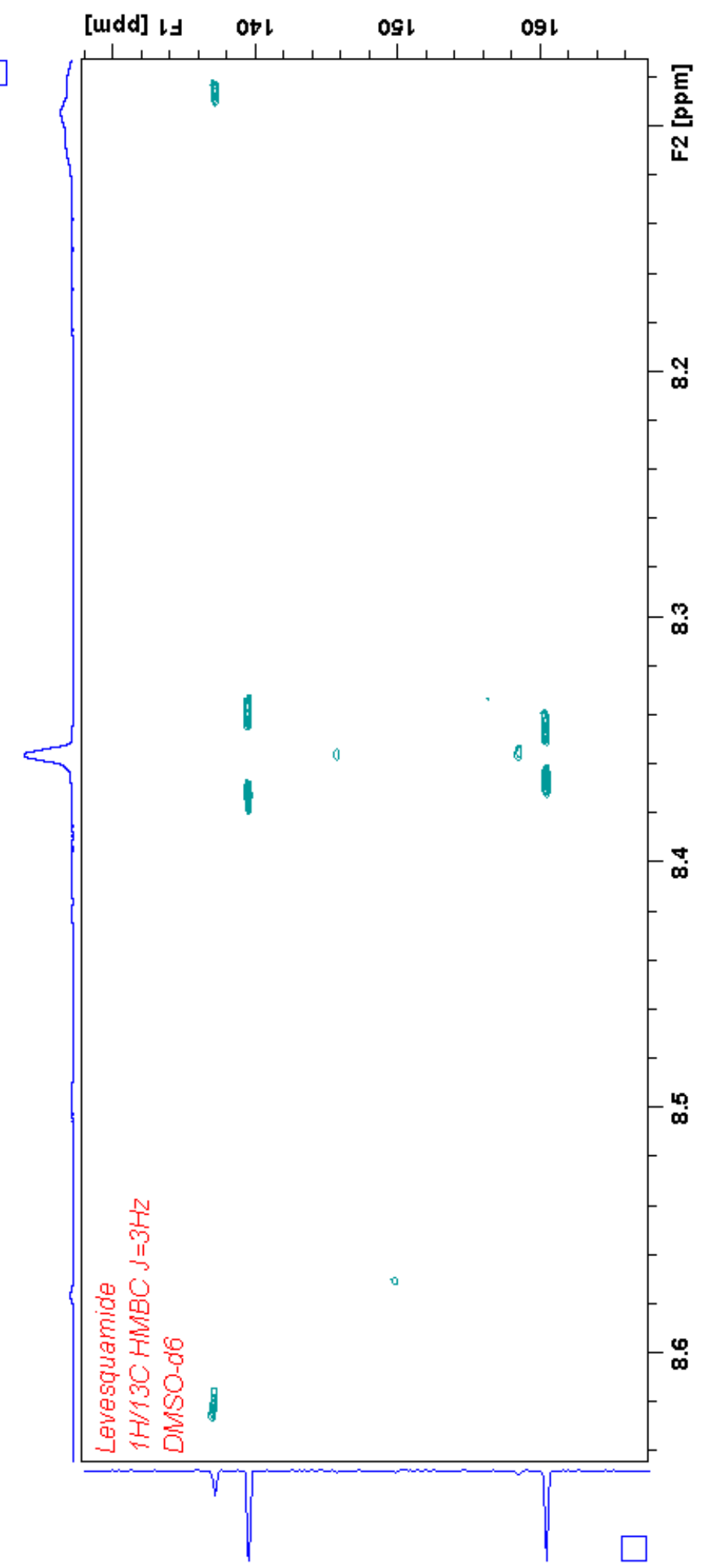

Figure S8. ${ }^{1} \mathrm{H}-{ }^{13} \mathrm{C}$ HMBC NMR $(400 / 100 \mathrm{MHz}, \mathrm{J}=3 \mathrm{~Hz})$ spectrum of levesquamide (1) in $\mathrm{DMSO}-d_{6}$. 


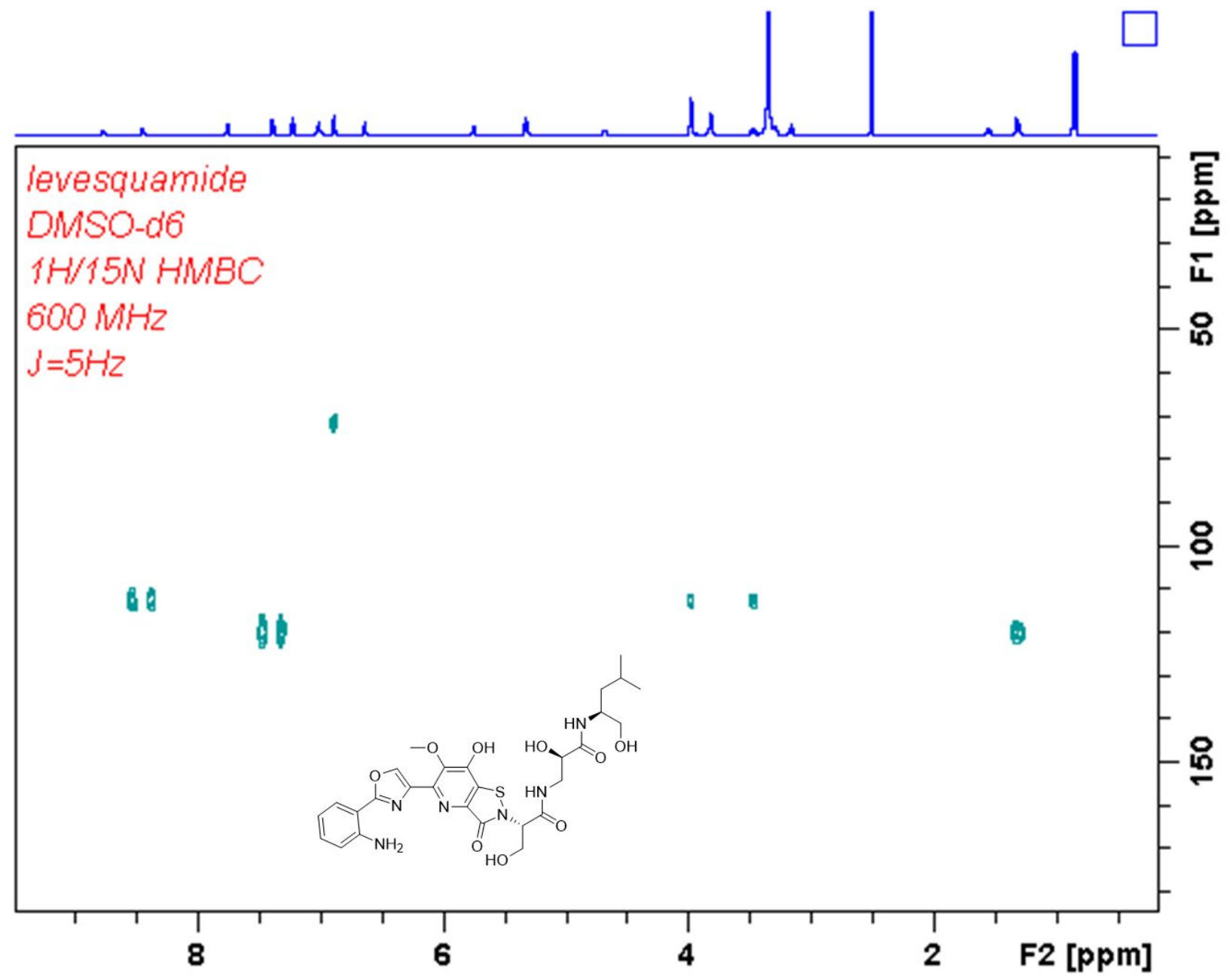

Figure S9. ${ }^{1} \mathrm{H}-{ }^{15} \mathrm{~N}$ HMBC NMR $(600 / 60 \mathrm{MHz}, \mathrm{J}=5 \mathrm{~Hz})$ spectrum of levesquamide (1) in DMSO- $d_{6}$. 


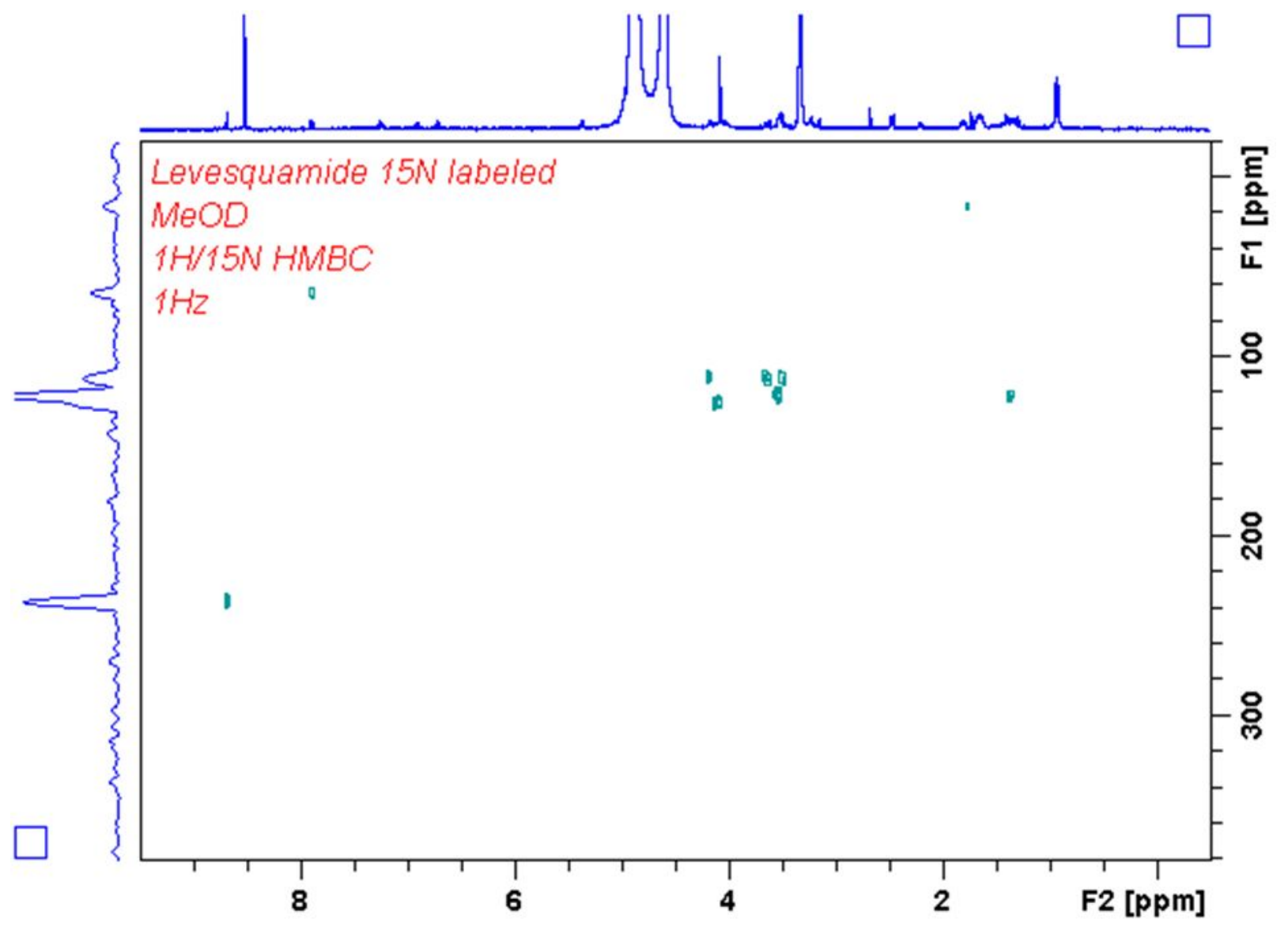

Figure S10. ${ }^{1} \mathrm{H}-{ }^{15} \mathrm{~N}$ HMBC NMR $(400 / 40 \mathrm{MHz}, \mathrm{J}=1 \mathrm{~Hz})$ spectrum of ${ }^{15} \mathrm{~N}-$ labeled levesquamide in MeOD. 


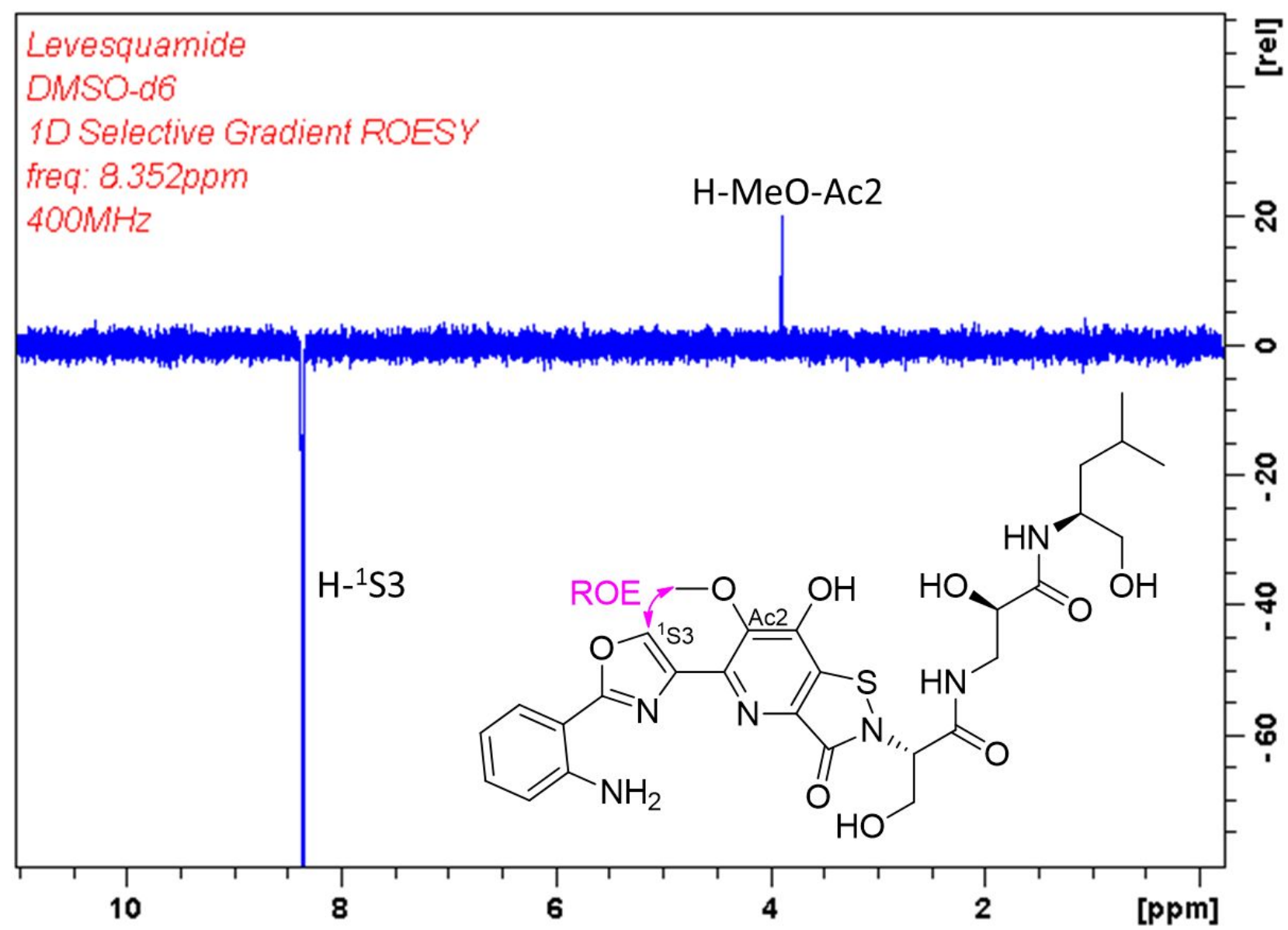

Figure S11. 1D selective ROESY NMR (400 MHz) spectrum of levesquamide (1) in DMSO- $d_{6}$. The $\mathrm{H}-{ }^{1} \mathrm{~S} 3$ proton $\left(\delta_{\mathrm{H}} 8.35\right)$ was irradiated and $\mathrm{H}-\mathrm{MeO}-\mathrm{Ac} 2\left(\delta_{\mathrm{H}} 3.97\right)$ was enhanced. 

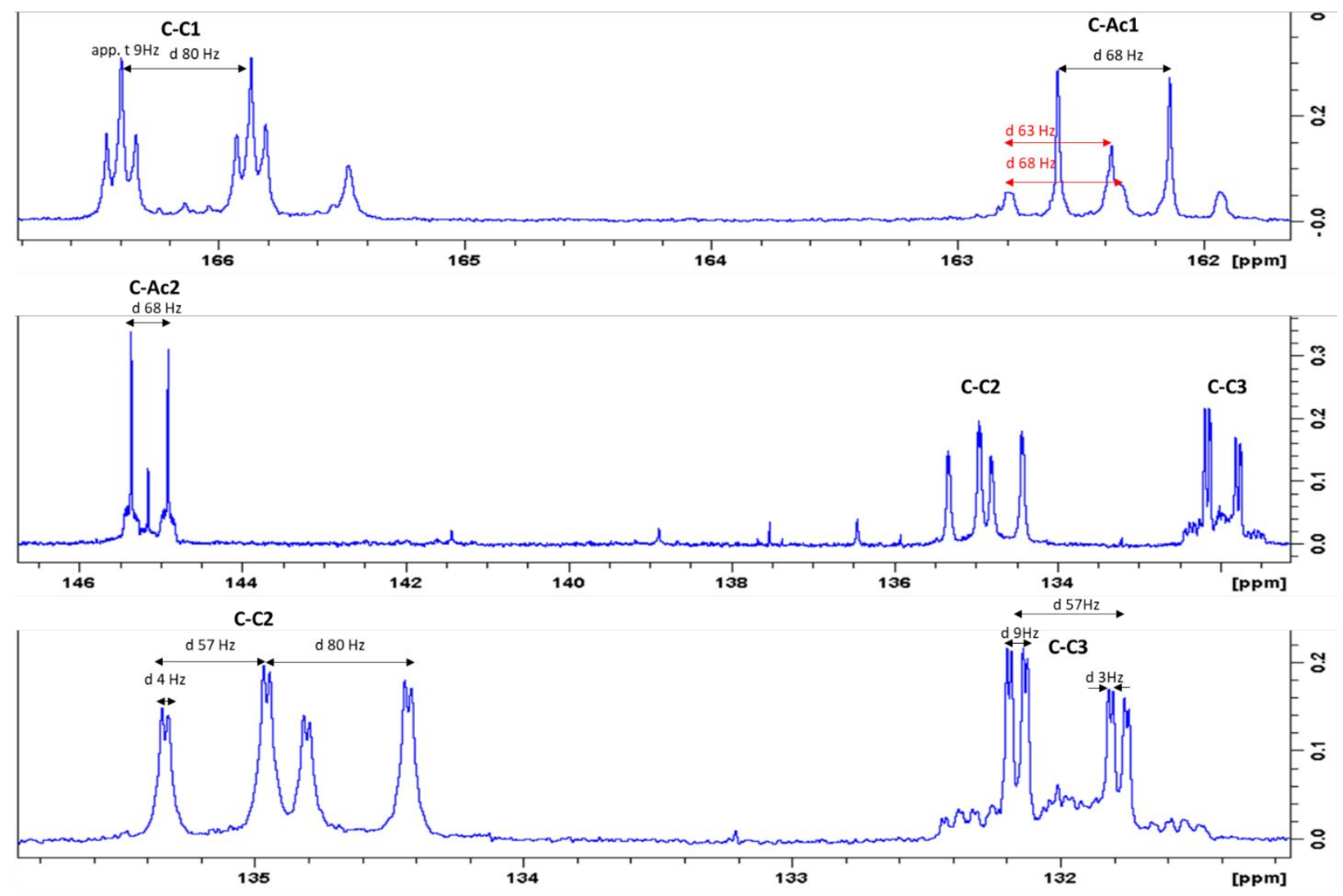

Figure S12. UDEFT ${ }^{13} \mathrm{C}$ NMR spectrum of $\mathrm{L}-\left[1,2,3-{ }^{13} \mathrm{C}_{3},{ }^{15} \mathrm{~N}\right]$ cysteine and sodium $\left[1,2-{ }^{13} \mathrm{C}_{2}\right]$ acetate labeled levesquamide (1). Coupling constants from the singly labeled constituents are highlighted in black and the doubly labeled constituent in red. 


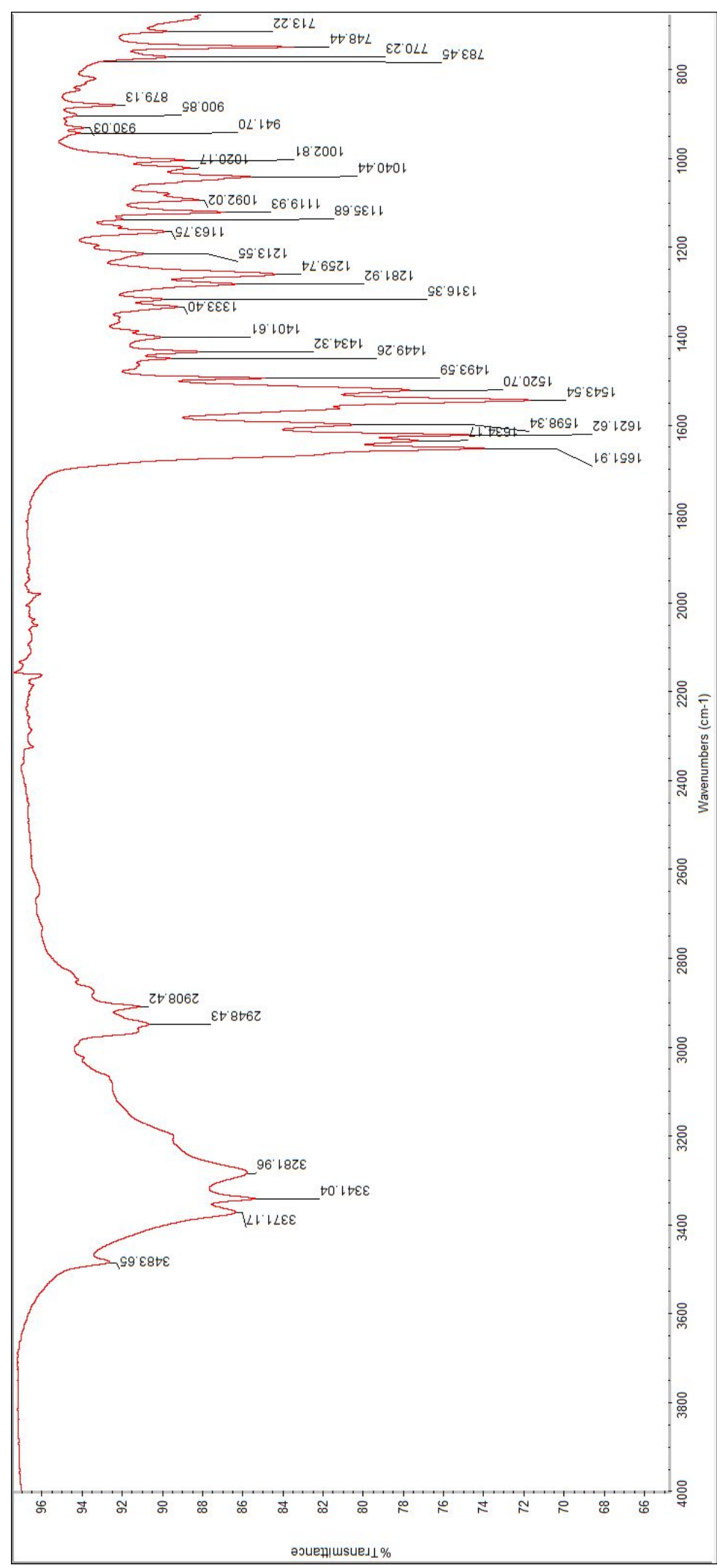

Figure S13. IR spectrum of levesquamide. 


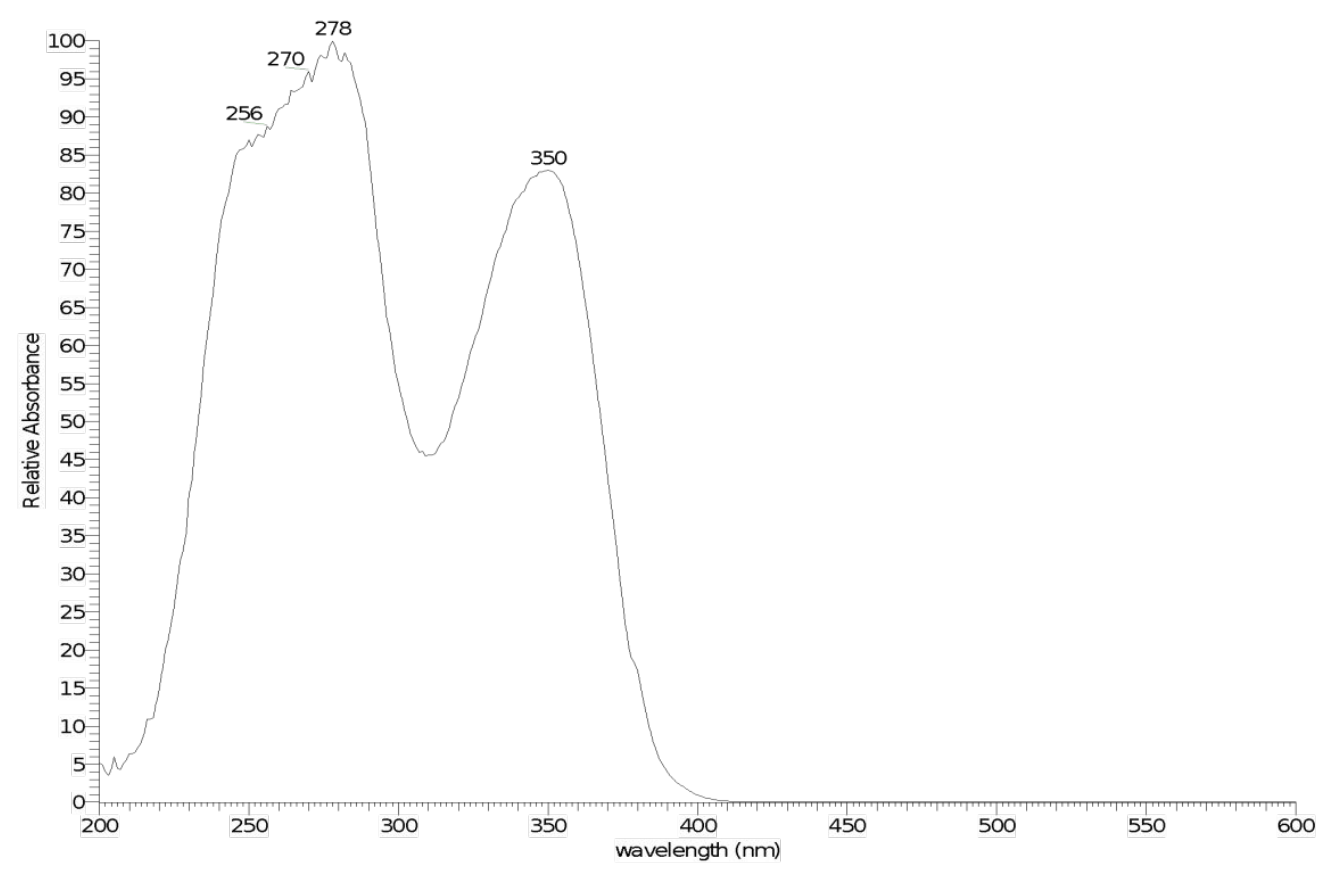

Figure S14. UV spectrum of levesquamide.

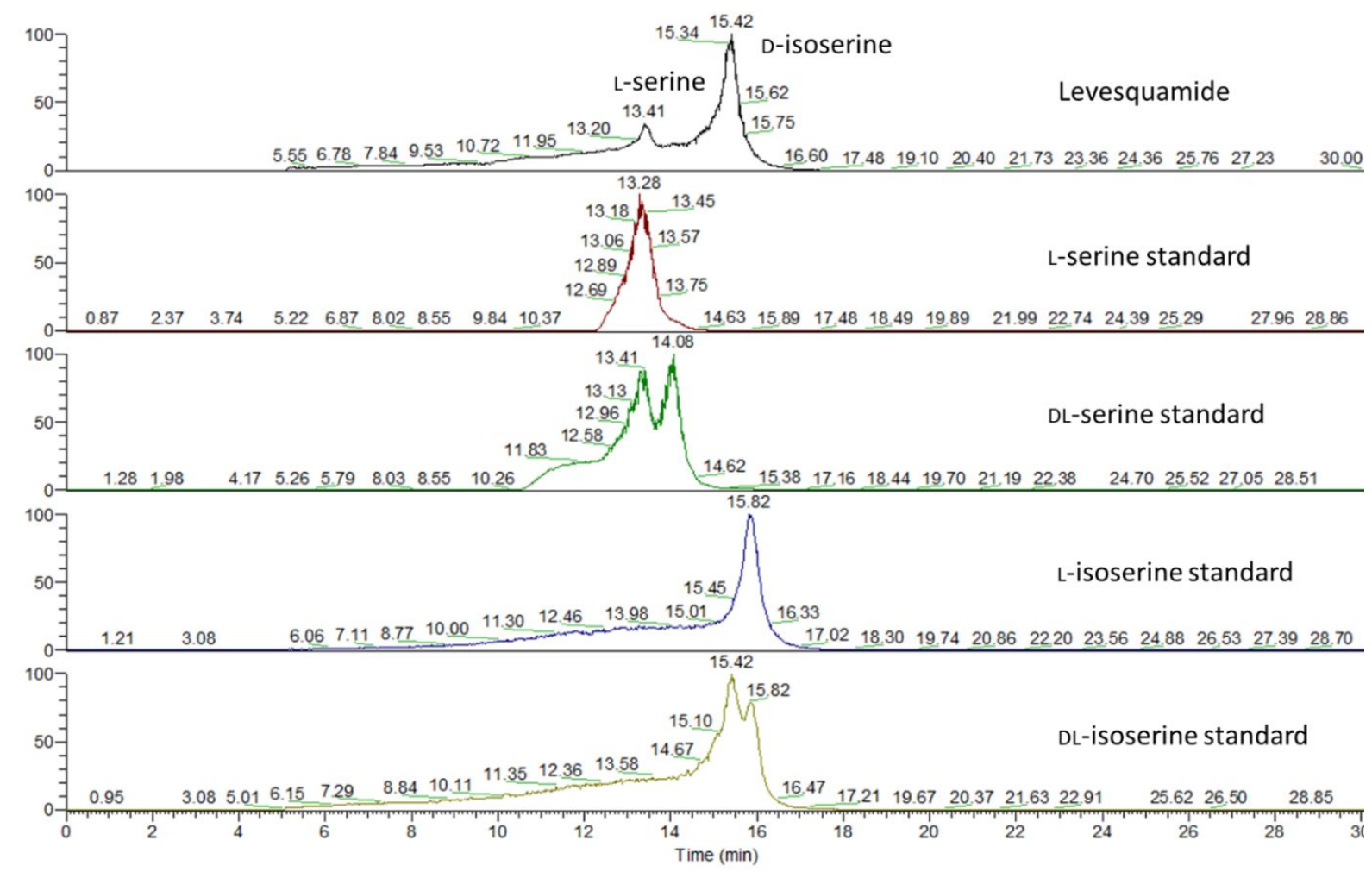

Figure S15. Marfey's analysis of serine and isoserine in levesquamide. 


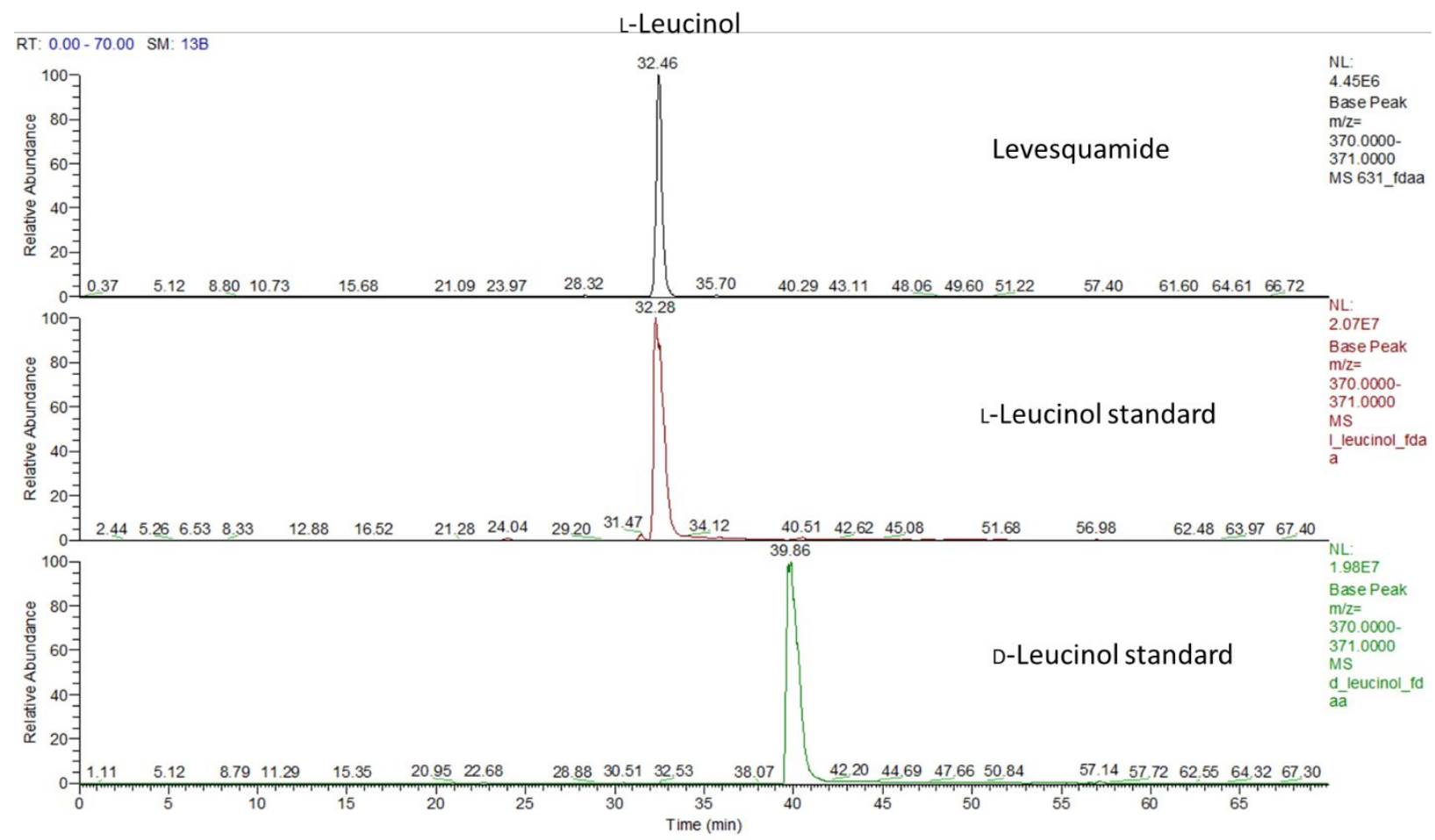

Figure S16. Marfey's analysis of leucinol in levesquamide. 

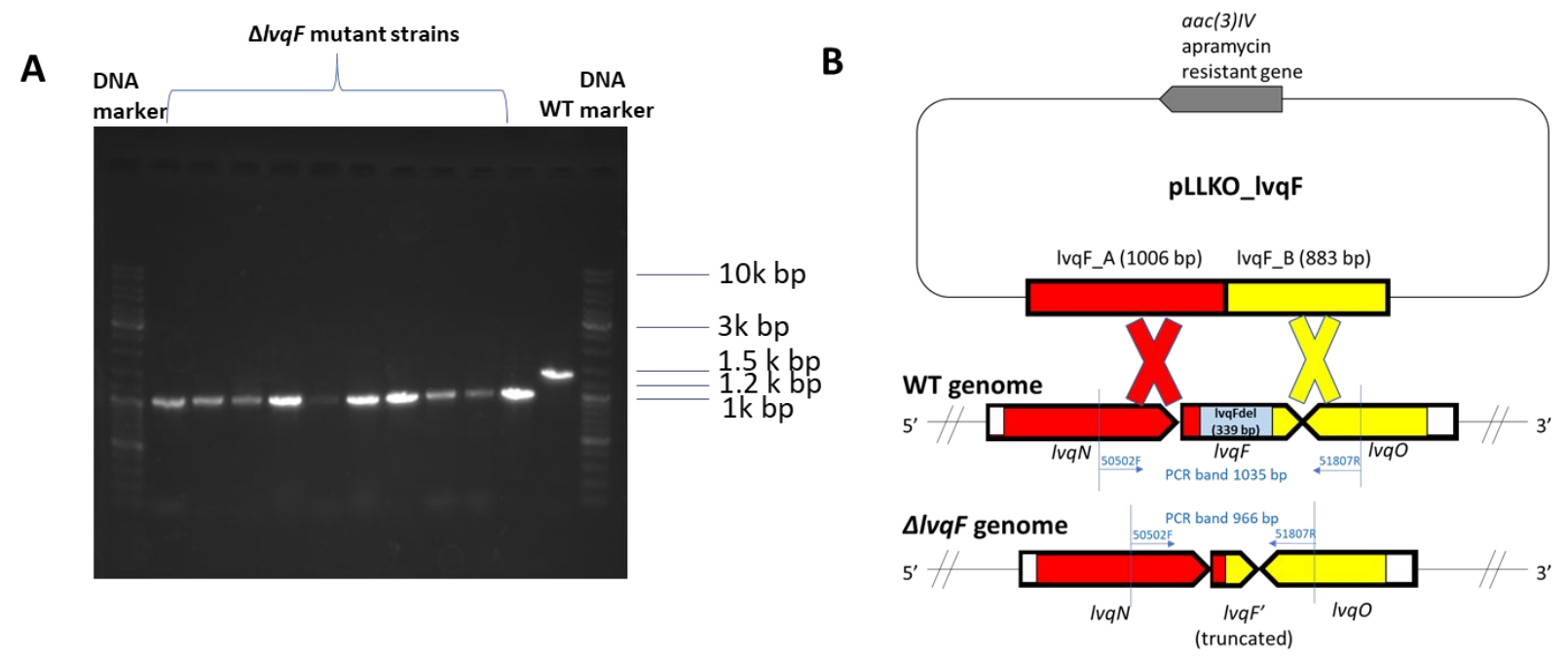

Figure S17. Inactivation scheme of $l v q F$. (A) Agarose gel electrophoresis of PCR amplicons from $\triangle l v q F$ mutant and wild-type (WT) strains. PCR primers were designed to amplify a 1305 bp from the WT strain and a $966 \mathrm{bp}$ amplicon from $\Delta l v q F$ mutants. DNA marker: GeneRuler DNA Ladder Mix (Thermo Scientific). (B) Overall knockout strategy using homologous recombination. PCR screening primers 50502F and 51807R are described in Table S4. 
A

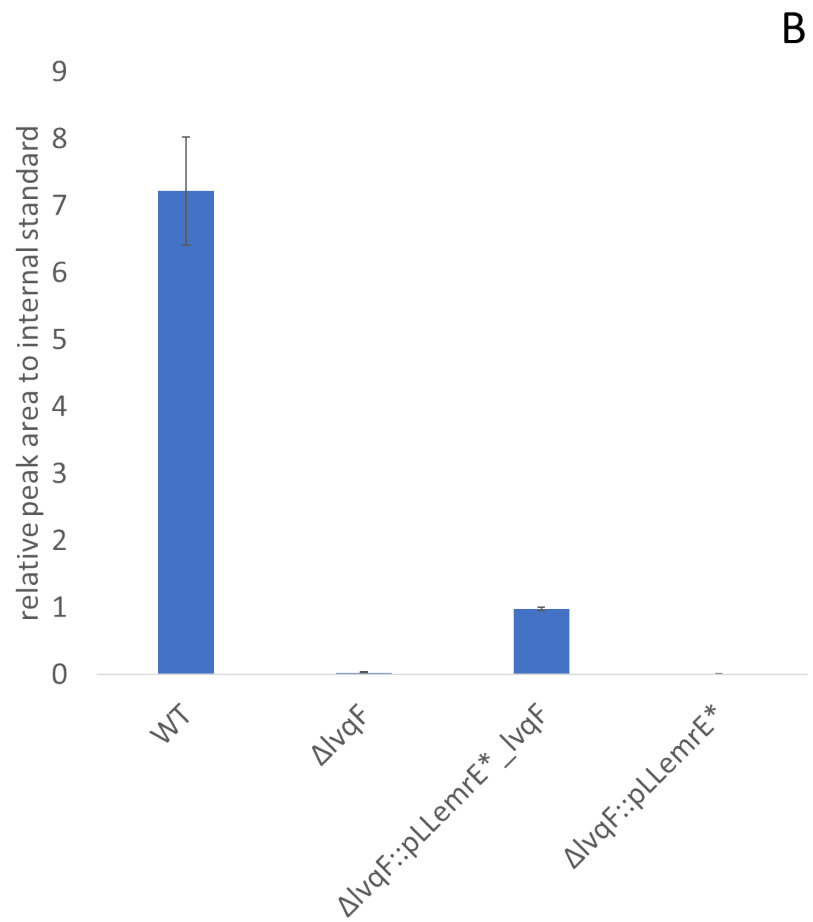

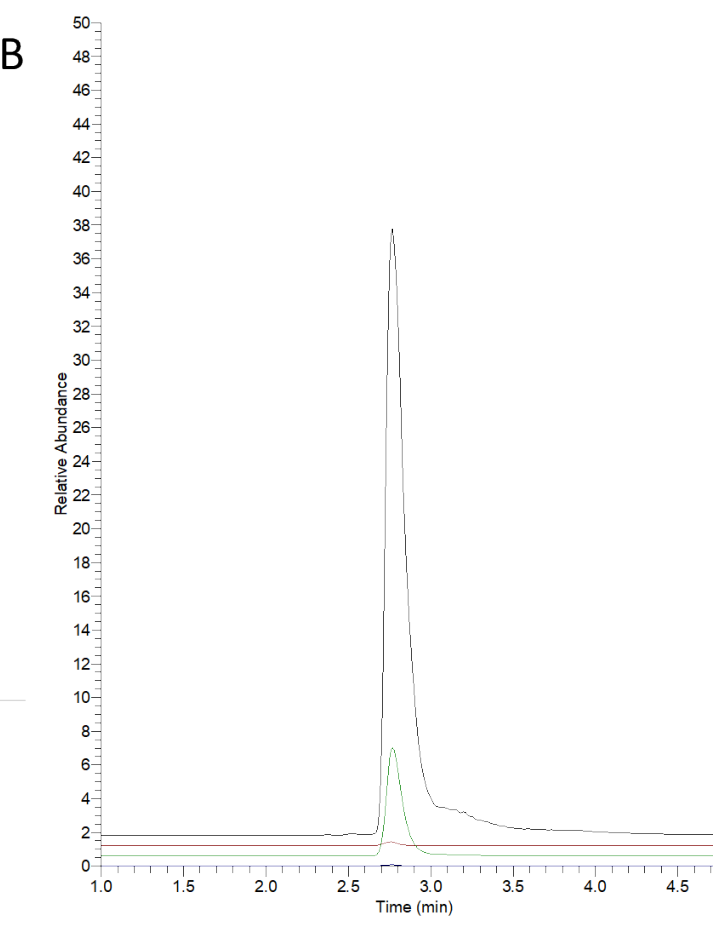

Figure S18. Production of levesquamide in wild-type (WT), $l v q F$ mutant and complemented strains. (A) Production of levesquamide by WT, $l v q F$ mutant and complemented strains. Peak areas were normalized to the internal standard, dioctyl phthalate at $10 \mu \mathrm{g} / \mathrm{mL}$. The experiment was performed in triplicate. (B) Representative UHPLC-HRMS chromatograms with selective ion monitoring of levesquamide $[\mathrm{M}+\mathrm{H}]^{+}$. From top to bottom: WT (black), $\Delta l v q F$ (red), $\Delta l v q F::$ pLLermE*_lvqF (green), and $\Delta l v q F:$ pLLermE* (blue). 
RT: $0.00-10.01$

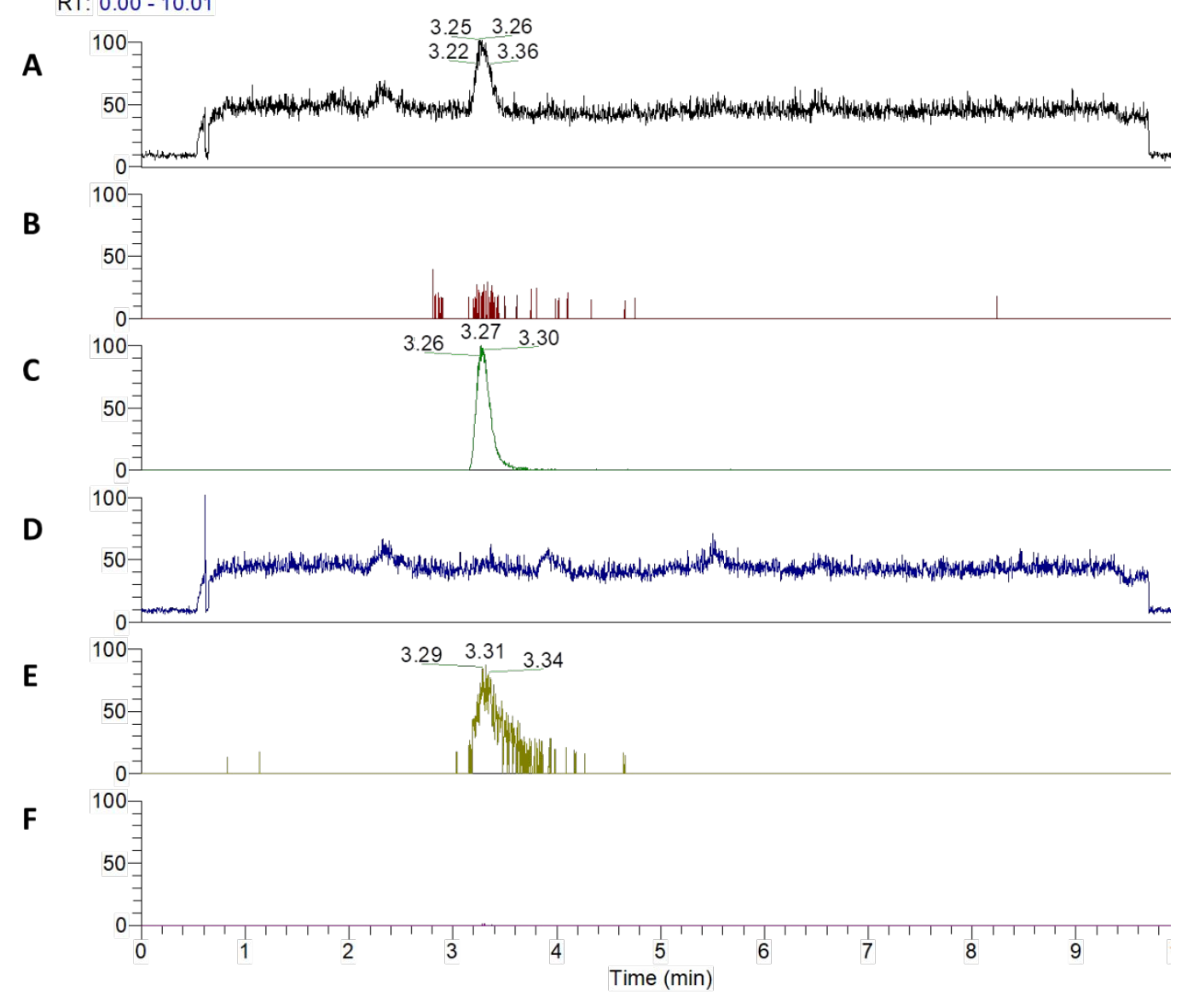

Figure S19. Chemical analysis of $l v q F$ deletion. (A) and (D) show total ion chromatograms of wild-type Streptomyces sp. RKND-216 and $\Delta l v q F$ mutant fermentation extracts at a mass intensity scale of 2E5. (B) and (E) show selected ion monitoring of desmethyl levesquamide $(\mathrm{m} / z 617.2024$ $[\mathrm{M}+\mathrm{H}]^{+}$) from wild-type and $\Delta l v q F$ mutant fermentation extracts at a mass intensity scale of $5 \mathrm{E} 3$. (C) and (F) show selected ion monitoring of levesquamide $\left(\mathrm{m} / \mathrm{z} 631.2180[\mathrm{M}+\mathrm{H}]^{+}\right)$from wild-type and $\Delta l v q F$ mutant fermentation extracts at a mass intensity scale of $7 \mathrm{E} 4$. 
Table S1. Biosynthetic gene cluster of levesquamide predicted by AntiSMASH 5.0.0.

\begin{tabular}{|c|c|c|c|c|}
\hline $\begin{array}{l}\text { Nucleotide } \\
\text { Location in } \\
\text { Contig } 1\end{array}$ & Protein & $\begin{array}{l}\text { AA } \\
\text { Length }\end{array}$ & $\begin{array}{l}\text { Proposed } \\
\text { Function in } \\
\text { Levesquamide }\end{array}$ & $\begin{array}{l}\text { Homologous Protein, } \\
\text { Origin, (\% Identity/\%Similarity), } \\
\text { Accession Number }\end{array}$ \\
\hline $\begin{array}{l}309,881- \\
311,170\end{array}$ & Orf19 & 429 & & $\begin{array}{l}\text { amine oxidase, Streptomyces sp. } \\
\text { CB02488, (69/77), OKK09866.1 }\end{array}$ \\
\hline $\begin{array}{l}308,395- \\
309,759\end{array}$ & Orf18 & 454 & & $\begin{array}{l}\text { deoxyribodipyrimidine photo-lyase, } \\
\text { Streptomyces sp. HCCB10043, (72/79), } \\
\text { ESU49083.1 }\end{array}$ \\
\hline $\begin{array}{l}306,116- \\
308,197\end{array}$ & Orf17 & 693 & & $\begin{array}{l}\text { Transmembrane transport protein, } \\
\text { Streptomyces sp. CBMAI 2042, } \\
(70 / 82), \text { RLV70998.1 }\end{array}$ \\
\hline $\begin{array}{l}305,527- \\
305,946^{\mathrm{c}}\end{array}$ & LvqR6 & 139 & $\begin{array}{l}\text { Transcriptional } \\
\text { regulator }\end{array}$ & $\begin{array}{l}\text { DNA-binding transcriptional regulator, } \\
\text { MarR family, Streptomyces glauciniger, } \\
\text { (72/84), SNR80269.1 }\end{array}$ \\
\hline $\begin{array}{l}304,018- \\
305,559\end{array}$ & LvqM & 513 & & $\begin{array}{l}\text { NAD }(\mathrm{P}) \mathrm{H}-\mathrm{dependent} \text { oxidoreductase, } \\
\text { Streptomyces chrestomyceticus JCM } \\
4735,(79 / 85), \text { GCD } 34214.1\end{array}$ \\
\hline $\begin{array}{l}302,516- \\
303,982\end{array}$ & LvqT4 & 488 & $\begin{array}{l}\text { Resistance/ } \\
\text { Efflux }\end{array}$ & $\begin{array}{l}\text { major facilitator transporter, Streptomyces } \\
\text { fradiae, }(72 / 81) \text {, KNE82682.1 }\end{array}$ \\
\hline $\begin{array}{l}301,870- \\
302,280^{c}\end{array}$ & Orf16 & 136 & & $\begin{array}{l}\text { Organic hydroperoxide reductase } \\
\text { OsmC/OhrA, Streptomyces qinglanensis, } \\
(48 / 58) \text {, SER66429.1 }\end{array}$ \\
\hline $\begin{array}{l}301,355- \\
301,762^{\mathrm{c}}\end{array}$ & Orf15 & 135 & & $\begin{array}{l}\text { hypothetical protein EHYA_07698, } \\
\text { Streptomyces hyalinus, }(44 / 50) \text {, } \\
\text { GCD99974.1 }\end{array}$ \\
\hline $\begin{array}{l}300,900- \\
301,109^{c}\end{array}$ & Orf14 & 69 & & $\begin{array}{l}\text { hypothetical protein, Streptomyces } \\
\text { formicae, }(65 / 79), \text { ATL28759.1 }\end{array}$ \\
\hline $\begin{array}{l}299,280- \\
300,695^{\mathrm{c}}\end{array}$ & Orf13 & 471 & & $\begin{array}{l}\text { sugar ABC transporter substrate-binding } \\
\text { protein, Streptomyces oceani, }(71 / 81) \text {, } \\
\text { OEV03027.1 }\end{array}$ \\
\hline $\begin{array}{l}298,863- \\
299,255\end{array}$ & LvqR5 & 130 & $\begin{array}{l}\text { Transcriptional } \\
\text { regulator }\end{array}$ & $\begin{array}{l}\text { LuxR family two component } \\
\text { transcriptional regulator, Streptomyces sp. } \\
\text { TLI_55, (48/62), SNX65705.1 }\end{array}$ \\
\hline $\begin{array}{l}298,238- \\
298,699\end{array}$ & LvqQ & 153 & & $\begin{array}{l}\text { VOC family protein, Streptomyces } \\
\text { armeniacus, (90/94), AXK32700.1 }\end{array}$ \\
\hline $\begin{array}{l}297,918- \\
298,241\end{array}$ & Orf12 & 107 & & $\begin{array}{l}\text { DinB family protein, } \text { Rhodococcus sp. } \\
\text { SMB37, (66/70), TCN55982.1 }\end{array}$ \\
\hline $\begin{array}{l}296,988- \\
297,875\end{array}$ & Orf11 & 295 & & $\begin{array}{l}\text { Cytochrome C biogenesis protein, } \\
\text { Streptomyces nanshensis, }(72 / 81) \\
\text { OEV28116.1 }\end{array}$ \\
\hline $\begin{array}{l}296,385- \\
296,975\end{array}$ & LvqP & 196 & & $\begin{array}{l}\text { Thiol-disulfide isomerase/thioredoxin, } \\
\text { Streptomyces sp. CNZ301, (42/57), } \\
\text { RZU78976.1 }\end{array}$ \\
\hline
\end{tabular}




\begin{tabular}{|c|c|c|c|c|}
\hline $\begin{array}{l}295,160- \\
296,110\end{array}$ & LvqR4 & 316 & $\begin{array}{l}\text { Transcriptional } \\
\text { regulator }\end{array}$ & $\begin{array}{l}\text { DNA-binding response regulator, } \\
\text { NarL/FixJ family, contains REC and } \\
\text { HTH domains, Micromonospora nigra, } \\
(46 / 61) \text {, SCL14748.1 }\end{array}$ \\
\hline $\begin{array}{l}294,058- \\
294,861^{\mathrm{c}}\end{array}$ & LvqN & 267 & $\begin{array}{l}\text { Anthranilate } \\
\text { precursor supply }\end{array}$ & $\begin{array}{l}\text { tryptophan 2,3-dioxygenase, Chloroflexi } \\
\text { bacterium, (56/69), TMD29316.1 }\end{array}$ \\
\hline $\begin{array}{l}293,414- \\
294,037\end{array}$ & LvqF & 207 & $\begin{array}{l}\text { O- } \\
\text { methyltransferase }\end{array}$ & $\begin{array}{l}\text { Methyltransferase domain-containing } \\
\text { protein, Streptomyces sp. WMMB } 322 \text {, } \\
(76 / 88), \text { SCK55890.1 }\end{array}$ \\
\hline $\begin{array}{l}292,344- \\
293,345\end{array}$ & LvqO & 333 & & $\begin{array}{l}\text { dTDP-glucose } 4,6 \text {-dehydratase, } \\
\text { Actinobacteria bacterium, }(42 / 56) \text {, } \\
\text { HCU95362.1 }\end{array}$ \\
\hline $\begin{array}{l}285,816- \\
292,052^{c}\end{array}$ & LvqA & 2078 & $\begin{array}{l}\text { NRPS modules } 1 \\
\text { and } 2\end{array}$ & $\begin{array}{l}\text { amino acid adenylation domain- } \\
\text { containing protein, Streptomyces sp. } \\
\text { CNZ301, (74/81), RZU89063.1 } \\
\text { acyl-CoA synthetase (AMP- }\end{array}$ \\
\hline $\begin{array}{l}284,816- \\
285,859^{c}\end{array}$ & LvqE & 347 & & $\begin{array}{l}\text { forming)/AMP-acid ligase II, } \\
\text { Streptomyces sp. BK161, (32/48), } \\
\text { TDT08592.1 }\end{array}$ \\
\hline $\begin{array}{l}283,981- \\
284,838\end{array}$ & LvqK & 285 & Oxidation & $\begin{array}{l}\text { Cupin-like domain-containing protein, } \\
\text { Streptomyces sp. WMMB 322, (71/82), } \\
\text { SCK 55914.1 }\end{array}$ \\
\hline $\begin{array}{l}282,151^{-} \\
283,671^{\mathrm{c}}\end{array}$ & LvqT3 & 506 & Transporter & $\begin{array}{l}\text { drug resistance transporter, EmrB/QacA } \\
\text { subfamily, Micromonospora } \\
\text { viridifaciens, }(48 / 60) \text {, SCF00046.1 }\end{array}$ \\
\hline $\begin{array}{l}281,353- \\
281,784^{c}\end{array}$ & LvqG & 143 & $\begin{array}{l}\text { Beta-alanine } \\
\text { biosynthesis } \\
\text { precursor supply }\end{array}$ & $\begin{array}{l}\text { L-aspartate 1-decarboxylase, } \\
\text { Streptomyces sp. CNZ301, (81/91), } \\
\text { RZU89059.1 }\end{array}$ \\
\hline $\begin{array}{l}273,454- \\
281,247^{c}\end{array}$ & LvqB & 2597 & $\begin{array}{l}\text { PKS-NRPS } \\
\text { modules } 3 \text { and } 4\end{array}$ & $\begin{array}{l}\text { non-ribosomal peptide } \\
\text { synthetase/polyketide synthase hybrid } \\
\text { protein, Streptomyces sp. CS40, (50/62), } \\
\text { CCC55921.1 }\end{array}$ \\
\hline $\begin{array}{l}270,143- \\
273,457^{\mathrm{c}}\end{array}$ & LvqC & 1104 & NRPS module 5 & $\begin{array}{l}\text { amino acid adenylation domain- } \\
\text { containing protein, Cylindrospermum sp. } \\
\text { NIES-4074, }(44 / 60) \text {, BAZ30183.1 }\end{array}$ \\
\hline $\begin{array}{l}262,453- \\
270,141^{\mathrm{c}}\end{array}$ & LvqD & 2562 & $\begin{array}{l}\text { NRPS modules } 6 \\
\text { and } 7 \text {, thioester } \\
\text { reductase }\end{array}$ & $\begin{array}{l}\text { amino acid adenylation domain- } \\
\text { containing protein, Micromonospora } \\
\text { viridifaciens, }(49 / 59) \text {, SCE99910.1 }\end{array}$ \\
\hline $\begin{array}{l}261,223- \\
262,431^{\mathrm{c}}\end{array}$ & $\mathrm{LvqH}$ & 402 & Oxidation & $\begin{array}{l}\text { 2-polyprenyl-6-methoxyphenol } \\
\text { hydroxylase-like FAD-dependent } \\
\text { oxidoreductase, Actinomadura pelletieri } \\
\text { DSM 43383, (37/53), RKS76991.1 }\end{array}$ \\
\hline
\end{tabular}




\begin{tabular}{|c|c|c|c|c|}
\hline $\begin{array}{l}259,934- \\
261,178^{c}\end{array}$ & LvqI & 414 & Dehydrogenation & $\begin{array}{l}\text { SCG54223.1; putative acyl-CoA } \\
\text { dehydrogenase, Streptomyces sp. CS40, } \\
(51 / 64), \text { CCC } 55923.1\end{array}$ \\
\hline $\begin{array}{l}259,164- \\
259,934^{\mathrm{c}}\end{array}$ & LvqJ & 256 & Thioesterase & $\begin{array}{l}\text { putative thioesterase, Hapalosiphonaceae } \\
\text { cyanobacterium JJU2, (44/63), } \\
\text { RAM51401.1; putative acyl-CoA } \\
\text { dehydrogenase, Streptomyces sp. CS40, } \\
\text { (41/55), CCC55924.1 } \\
\text { NA-binding response regulator, }\end{array}$ \\
\hline $\begin{array}{l}58,408 \\
59,139\end{array}$ & LvqR3 & 243 & $\begin{array}{l}\text { Transcriptional } \\
\text { regulator }\end{array}$ & $\begin{array}{l}\text { NarL/FixJ family, contains REC and } \\
\text { HTH domains, Micromonospora } \\
\text { mirobrigensis, (41/59), SCE78082.1 }\end{array}$ \\
\hline $\begin{array}{l}257,092- \\
258,381\end{array}$ & LvqR2 & 429 & $\begin{array}{l}\text { Transcriptional } \\
\text { regulator }\end{array}$ & $\begin{array}{l}\text { NA-binding transcriptional regulator, } \\
\text { MurR/RpiR family, contains HTH and } \\
\text { SIS domains, Streptomyces indicus, } \\
(55 / 70) \text {, SDJ58583.1 }\end{array}$ \\
\hline $\begin{array}{l}256,508- \\
256,702^{c}\end{array}$ & Orf10 & 64 & & $\begin{array}{l}\text { uncharacterized protein LOC } 111610001 \text {, } \\
\text { Xiphophorus maculatus, (43/51), } \\
\text { XP_023197627.1 }\end{array}$ \\
\hline $\begin{array}{l}256,255- \\
256,446^{c}\end{array}$ & Orf9 & 63 & & $\begin{array}{l}\text { hypothetical protein SPW_3475, } \\
\text { Streptomyces sp. W007, } \\
(71 / 79), \text { EHM } 28126.1\end{array}$ \\
\hline $\begin{array}{l}255,603- \\
256,007\end{array}$ & Orf8 & 134 & & $\begin{array}{l}\text { Transposase, Streptomyces } \\
\text { zhaozhouensis, (88/94), SOD66942.1 }\end{array}$ \\
\hline $\begin{array}{l}254,237- \\
255,349\end{array}$ & Orf7 & 370 & & $\begin{array}{l}\text { Band } 7 \text { protein, Streptomyces sp. CBMAI } \\
2042,(86 / 91), \text { RLV69272. }\end{array}$ \\
\hline $\begin{array}{l}253,770- \\
254,207\end{array}$ & Orf6 & 145 & & $\begin{array}{l}\text { membrane protein, Streptomyces } \\
\text { olindensis, }(87 / 92), \text { KDN76860.1 }\end{array}$ \\
\hline $\begin{array}{l}253,403- \\
253,708^{c}\end{array}$ & Orf5 & 101 & & $\begin{array}{l}\text { hypothetical protein EDD3944646, } \\
\text { Kitasatospora cineracea, }(4 \overline{6} / 58), \\
\text { ROR46379.1 }\end{array}$ \\
\hline $\begin{array}{l}252,897- \\
253,061^{c}\end{array}$ & LvqS & 54 & & $\begin{array}{l}\text { pyridine nucleotide-disulfide } \\
\text { oxidoreductase, Streptomyces kanasensis, } \\
\text { (80/82), KUH35663.1 }\end{array}$ \\
\hline $\begin{array}{l}252,169- \\
252,846^{\mathrm{c}}\end{array}$ & Orf4 & 225 & & $\begin{array}{l}\text { haloacid dehalogenase type II, } \\
\text { Streptomyces sp., (62/72), HCA } 86009.1\end{array}$ \\
\hline $\begin{array}{l}251,252- \\
251,851\end{array}$ & LvqR1 & 199 & $\begin{array}{l}\text { Transcriptional } \\
\text { regulator }\end{array}$ & $\begin{array}{l}\text { HTH-type transcriptional repressor } \\
\text { ComR, Streptomyces jeddahensis, } \\
(73 / 83) \text {, OAH10369.1 }\end{array}$ \\
\hline $\begin{array}{l}250,500- \\
251,147^{c}\end{array}$ & LvqR & 215 & & $\begin{array}{l}\text { alkyl hydroperoxide reductase, } \\
\text { Streptomyces nanshensis, }(78 / 87) \text {, } \\
\text { OEV29300.1 }\end{array}$ \\
\hline
\end{tabular}

butyryl-CoA dehydrogenase, Micromonospora halophytica, (64/73), SCG54223.1; putative acyl-CoA dehydrogenase, Streptomyces sp. CS40, (51/64), CCC55923.1

putative thioesterase, Hapalosiphonaceae cyanobacterium JJU2, (44/63), dehydrogenase, Streptomyces sp. CS40, (41/55), CCC55924.1

NA-binding response regulator NarL/FixJ family, contains REC and (2) NA-binding transcriptional regulator, MurR/RpiR family, contains HTH and SIS domains, Streptomyces indicus, (55/70), SDJ58583.1 uncharacterized protein LOC111610001, Xiphophorus maculatus, (43/51) XP_023197627.1

hypothetical protein SPW_3475, Streptomyces sp. W007, (71/79), EHM28126.1

Transposase, Streptomyces zhaozhouensis, (88/94), SOD66942.1 Band 7 protein, Streptomyces sp. CBMAI 2042, (86/91), RLV69272. membrane protein, Streptomyces olindensis, (87/92), KDN76860.1 hypothetical protein EDD39_4646, Kitasatospora cineracea, $(46 / 58)$ pyridine nucleotide-disulfide oxidoreductase, Streptomyces kanasensis, (80/82), KUH35663.1

haloacid dehalogenase type II, Streptomyces sp., (62/72), HCA86009.1

HTH-type transcriptional repressor ComR, Streptomyces jeddahensis, (73/83), OAH10369.1 Streptomyces nanshensis, $(78 / 87$ OEV29300.1 
$249,615-$

$249,893^{c}$

$247,942-$

$249.291^{\mathrm{c}}$

246,693-

247,892

$245,153-$

$246,466^{c}$

$244,211-$

$245,146^{c}$

243,396-

$244,211^{\mathrm{c}}$

Orf3 122

LvqL 449

Orf2 399
Orf1 437

LvqT2 $311 \quad$ Transporter

LvqT1 $271 \quad$ Transporter

phage integrase, Streptomyces laurentii, (78/84), BAU84714.1

NADH dehydrogenase, Streptomyces nanshensis, (78/87), OEV31532.1

thiolase family protein, Streptomyces armeniacus, (90/94), AXK32523.1 sugar ABC transporter substrate-binding protein, Streptomyces armeniacus, (74/85), AXK37157.1 sugar ABC transporter permease, Streptomyces armeniacus, (87/93), AXK37158.1 carbohydrate ABC transporter permease, Streptomyces armeniacus, (85/94), AXK32525.1

${ }^{c}$ transcription from the complimentary DNA strand 
Table S2. Analysis of the LvqA CAL domain specificity conferring residues according to the 10 aa code. ${ }^{1}$

\begin{tabular}{lcccccccccccc}
\hline Proteins/ & & \multicolumn{10}{c}{ Amino Acid Position* } \\
Modules & 235 & 236 & 239 & 278 & 299 & 301 & 322 & 330 & 331 & 517 & Substrate & $D$ \\
\hline LvqA-CAL & A & L & A & S & F & A & G & L & G & K & Ant & - \\
anaPS_A1 & G & A & L & F & F & A & A & G & V & K & Ant (f) & 116 \\
PqsA & G & Y & G & F & F & A & G & H & V & K & Ant & 117 \\
BLM-NH2 & D & M & V & S & Y & G & T & L & L & K & NH & 128 \\
EncN & A & Y & G & F & V & A & G & H & I & K & Benz & 140 \\
YbtE & N & F & C & A & Q & G & V & L & C & K & Sal & 141 \\
ABE31536 & A & Y & G & Y & T & A & G & H & I & K & Benz & 146 \\
AAL02069 & T & F & G & F & V & A & G & H & I & K & Ant & 149 \\
ABE35671 & T & F & G & F & V & A & G & H & I & K & Ant & 149 \\
AuaEII & T & F & G & Y & V & A & G & H & I & K & Ant & 153 \\
FAAL & D & M & I & L & A & G & V & V & G & K & FA & 153 \\
PchD & N & F & C & A & Q & G & V & I & C & K & Sal & 162 \\
AAN10109 & V & V & F & F & T & A & I & N & S & K & 4-Cl-Benz & 162 \\
GrsA-PheA & D & A & W & T & I & A & A & I & C & K & L-Phe & 167 \\
DhbE & N & Y & S & A & Q & G & V & V & N & K & DHB & 195 \\
EntE & N & Y & S & A & Q & G & V & V & N & K & DHB & 195
\end{tabular}

* aa numbering is based on the A domain of GrsA that activates L-Phe. $D$ - cumulative aa dissimilarity score to the LvqA-CAL specificity code calculated using Sneath's Index. ${ }^{2}$ Abbreviations: Ant, anthranilate; Ant (f), anthranilate from a fungal NRPS; NH2, CAL domain involved in $\beta$-aminoalaninamide biosynthesis, Benz, benzoic acid; Sal - salicylic acid, 4-Cl-Benz, 4-chlorobenzoic acid; FA, fatty acid; DHB, 2,3-dihydroxybenzoic acid. Proteins/modules: anaPS_A1, fungal anthranilate-activating A domain from Nesosartory fisheri NRRL 18; PqsA, PQS biosynthesis stand alone anthranilate CoA ligase from Pseudomonas aeruginosa (accession no. AAG04385); ${ }^{4}$ BLM-NH2, bleomycin CAL domain from the BlmVI loading domain involved in $\beta$-aminoalaninamide biosynthesis in Streptomyces verticillus (accession no. AAG02359); EncN, enterocin biosynthesis benzoate CoA ligase from Streptomyces maritimus (accession no. AAF81733); YbtE, yersinabactin biosynthesis salicylate A domain from Yersinia pestis (accession no. AAC69591); ABE31536, accession no. of Burkholderia xenovorans LB400 benzoate CoA ligase; AAL02069, accession no. of Arzoarcus evansii anthranilate CoA ligase; ABE35671, accession no. of Burkholderia xenovorans LB400 anthranilate CoA ligase; AuaEII, aurachin biosynthesis standalone anthranilate CoA ligase from Stigmatella aurantiaca (accession no. CCA65703); ${ }^{5}$ FAAL, bacillomycin L biosynthesis fatty acid CoA ligase NRPS domain from Bacillus subtilus A1/3 (accession no. AAQ07410); PchD, pyochelin biosynthesis salicylate A domain from Pseudomonas aeruginosa UCBPP-PA14 (accession no. AAD55799); AAN10109, accession no. of Alcanigenes sp. AL3007 4-chlorobenzoate CoA ligase; GrsA-PheA - gramicidin S biosynthesis L-Phe activating A domain from Brevibacillus brevis (accession no. AAA58718); DhbE, bacillibactin biosynthesis stand alone dihydroxybenzoate A domain from Bacillus subtilis (accession no. AY138812); EntE, enterobactin biosynthesis stand alone dihydroxybenzoate A domain from Escherichia coli (accession no. 1610172A). 
Table S3. Analysis of the levesquamide NRPS A domains specificity conferring residues according to the 10 aa code. ${ }^{1}$

\begin{tabular}{|c|c|c|c|c|c|c|c|c|c|c|}
\hline \multirow{2}{*}{$\begin{array}{l}\text { Protein-Module } \\
\text { (substrate) }\end{array}$} & \multicolumn{10}{|c|}{ Amino Acid Position* } \\
\hline & 235 & 236 & 239 & 278 & 299 & 301 & 322 & 330 & 331 & 517 \\
\hline LvqA-M2 (Ser) & $\mathrm{D}$ & $\mathrm{L}$ & $\mathrm{G}$ & $\mathrm{N}$ & $\mathrm{W}$ & $\mathrm{S}$ & $\mathrm{S}$ & I & $\mathrm{W}$ & $\mathrm{K}$ \\
\hline LvqB-M4 (Cys) & $\mathrm{D}$ & $\mathrm{L}$ & $\mathrm{Y}$ & $\mathrm{N}$ & $\mathrm{L}$ & $\mathrm{S}$ & $\mathrm{L}$ & $\mathrm{V}$ & W & $\mathrm{K}$ \\
\hline LvqC-M5 (Ser) & $\mathrm{D}$ & $\mathrm{V}$ & $\mathrm{Y}$ & $\mathrm{S}$ & $\mathrm{I}$ & A & $\mathrm{I}$ & $\mathrm{V}$ & $\mathrm{H}$ & $\mathrm{K}$ \\
\hline LvqD-M6 ( $\beta$-Ala) & $\mathrm{D}$ & M & $\mathrm{L}$ & Q & $\mathrm{L}$ & $\mathrm{G}$ & $\mathrm{V}$ & $\mathrm{V}$ & $\mathrm{W}$ & $\mathrm{K}$ \\
\hline LvqD-M7 (Leu) & $\mathrm{D}$ & & $\mathrm{W}$ & & $\mathrm{V}$ & $\mathrm{G}$ & A & V & $\mathrm{Y}$ & $\mathrm{K}$ \\
\hline \multicolumn{11}{|l|}{ Ser Consensus } \\
\hline \multicolumn{11}{|l|}{ Thr Consesnsu } \\
\hline \multicolumn{11}{|l|}{ Cys Consensus } \\
\hline \multicolumn{11}{|l|}{ Leu Consensus } \\
\hline \multicolumn{11}{|l|}{ Gly Consensus } \\
\hline \multicolumn{11}{|l|}{$\beta$-Ala Consensus ${ }^{\bar{\top}}$} \\
\hline$\beta$-Ala-KirB & $\mathrm{D}$ & $\mathrm{T}$ & $\mathrm{L}$ & Q & $\mathrm{L}$ & $\mathrm{G}$ & $\mathrm{V}$ & $\mathrm{I}$ & $\mathrm{W}$ & $\mathrm{K}$ \\
\hline $\operatorname{LvqE}^{\#}$ & - & - & $\mathrm{T}$ & $\mathrm{H}$ & - & - & $\mathrm{D}$ & A & $\mathrm{T}$ & $\mathrm{K}$ \\
\hline
\end{tabular}


* aa numbering is based on the A domain of GrsA that activates L-Phe. Consensus domain specificity conferring codes were extracted from previously reported alignments. ${ }^{6,7}$ The size of residues indicates the frequency of the aa at each position.

${ }^{\bar{T}}$ The $\beta$-Ala consensus compiled from previously reported alignments ${ }^{6,7}$ was updated to include the recently reported specificity conferring code from the $\beta$-Ala activating Adomain in module three of TnaP from the theonellamide biosynthetic gene cluster. ${ }^{8}$

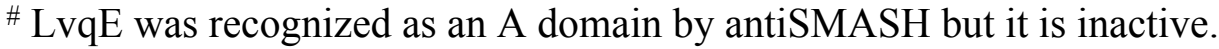

Table S4. PCR primers in the study.

\begin{tabular}{|c|c|}
\hline Primer Name & Primer Sequence $\left(5^{\prime}-3^{\prime}\right)$ \\
\hline LvqFKO A F & gcttgggctgcaggtcgactctagaCCTCCCACTCGGGCAAAG \\
\hline LvqFKO_A_R & gcaccaccagTTGCACGAGGTTCTCGCG \\
\hline LvqFKO_B_F & cetcgtgcaaCTGGTGGTGCTGTGGTGTTTC \\
\hline LvqFKO_B_R & acagctatgacatgattacgaattcCGAGGTACACCGACCTGC \\
\hline ErmE*_F $^{*}-$ & gcttgggetgcaggtcgactctagaAGCTCGGTACCAGCCCGA \\
\hline ErmE*_R & ctccttctctAGGATCCTACCAACCGGC \\
\hline LvqF_R̄BS_F & gtaggatcctAGAGAAGGAGAACGTCGTG \\
\hline LvqF_RBS_R & acagctatgacatgattacgaattcTCACCTGCGGGTCATCAG \\
\hline $50502 \mathrm{~F}$ & GTGTCCTGGGCCACCTGCTCAG \\
\hline $51807 \mathrm{R}$ & CTCCGACGTGCTCGCCGTG \\
\hline M13_F & GTAAAACGACGGCCAG \\
\hline $600 \_\bar{F}$ & GGAACACGGCCGAGCAG \\
\hline $124 \overline{6} \_\mathrm{F}$ & GGGATCACAGCCGGGTAC \\
\hline 1608 F & GAACCTCGTGCAACTGGTG \\
\hline M13_R & CAGGAAACAGCTATGAC \\
\hline $671 \overline{\mathrm{R}}$ & GCGGTGAGCTGTCGACC \\
\hline $120 \overline{8} \_\mathrm{R}$ & GCACGCCATCTTGGAGTC \\
\hline 2003_R & GACGAACTCTTCAGCACG \\
\hline $5050 \overline{2} \mathrm{~F}$ & GTGTCCTGGGCCACCTGCTCAG \\
\hline $51807 \mathrm{R}$ & CTCCGACGTGCTCGCCGTG \\
\hline $242 \_258 \_F$ & GATGCTGTTGTGGGCAC \\
\hline
\end{tabular}




\section{References}

(1) (a) Stachelhaus, T.; Mootz, H. D.; Marahiel, M. A. The specificity-conferring code of adenylation domains in nonribosomal peptide synthetases. Chem. Biol. 1999, 6, 493-505. (b) Challis, G. L.; Ravel, J.; Townsend, C. A. Predictive, structure-based model of amino acid recognition by nonribosomal peptide synthetase adenylation domains. Chem. Biol. 2000, 7, 211-224.

(2) Sneath, P. Relations between chemical structure and biological activity in peptides. J. Theor. Biol. 1966, 12, 157-195.

(3) Ames, B. D.; Walsh, C. T. Anthranilate-activating modules from fungal nonribosomal peptide assembly lines. Biochemistry (N. Y. ) 2010, 49, 3351-3365.

(4) Coleman, J. P.; Hudson, L. L.; McKnight, S. L.; Farrow, J. M.,3rd; Calfee, M. W.; Lindsey, C. A.; Pesci, E. C. Pseudomonas aeruginosa PqsA is an anthranilate-coenzyme A ligase. J. Bacteriol. 2008, 190, 1247-1255.

(5) Pistorius, D.; Li, Y.; Mann, S.; Müller, R. Unprecedented anthranilate priming involving two enzymes of the acyl adenylating superfamily in aurachin biosynthesis. J. Am. Chem. Soc. 2011, 133, 1236212365.

(6) Minowa, Y.; Araki, M.; Kanehisa, M. Comprehensive analysis of distinctive polyketide and nonribosomal peptide structural motifs encoded in microbial genomes. J. Mol. Biol. 2007, 368, $1500-1517$.

(7) Raushch, C.; Weber, T.; Kohlbacher, O.; Wohlleben, W.; Huson, D. H. Specificity prediction of adenylation domains in nonribosomal peptide synthetases (NRPS) using transductive support vector machines (TSVMs). Nucl. Acids Res. 2005, 33, 5799-5808.

(8) Mori, T.; Cahn, J.K.; Wilson, M.C.; Meoded, R.A.; Wiebach, V.; Martinez, A.F.C.; Helfrich, E.J.; Albersmeier, A.; Wibberg, D.; Dätwyler, S.; Keren, R.; Lavy, A.; Ruckert C.; Ilan M., Kalinowski J.; Matsunaga S.; Takeyama H.; Piel J. Single-bacterial genomics validates rich and varied specialized metabolism of uncultivated Entotheonella sponge symbionts. Proc. Natl. Acad. Sci. U. S. A. $2018,115,1718-1723$. 